\title{
Relevance of regulatory T cell promotion of donor-specific tolerance in solid organ transplantation
}

\author{
Pervinder Sagoo ${ }^{1,2}$, Giovanna Lombardi $^{1}$ and Robert I. Lechler ${ }^{1 *}$ \\ Department Transplantation, Immunoregulation and Mucosal Biology, MRC Centre for Transplantation, King's College London, London, UK \\ ${ }^{2}$ NIHR Biomedical Research Centre, Guy's and St. Thomas' NHS Foundation Trust and King's College London, London, UK
}

\section{Edited by:}

Stephen P. Cobbold, University of

Oxford, UK

Reviewed by:

Ani Chandraker, Brigham and

Women's Hospital, USA

Thomas Wekerle, Medical

University of Vienna, Austria

\section{*Correspondence:}

Robert I. Lechler, Vice-Principal and Director of King's Health Partners

Academic Health Sciences Centre,

King's College London, Great Maze

Pond, London SE1 9RT, UK.

e-mail: robert.lechler@kcl.ac.uk
Current clinical strategies to control the alloimmune response after transplantation do not fully prevent induction of the immunological processes which lead to acute and chronic immune-mediated graft rejection, and as such the survival of a solid organ allograft is limited. Experimental research on naturally occurring $\mathrm{CD} 4^{+} \mathrm{CD} 25^{\text {high }} \mathrm{FoxP} 3^{+}$Regulatory $T$ cells (Tregs) has indicated their potential to establish stable long-term graft acceptance, with the promise of providing a more effective therapy for transplant recipients. Current approaches for clinical use are based on the infusion of freshly isolated or ex vivo polyclonally expanded Tregs into graft recipients with an aim to redress the in vivo balance of $\mathrm{T}$ effector cells to Tregs. However mounting evidence suggests that regulation of donor-specific immunity may be central to achieving immunological tolerance. Therefore, the next stages in optimizing translation of Tregs to organ transplantation will be through the refinement and development of donor alloantigen-specific Treg therapy. The altering kinetics and intensity of alloantigen presentation pathways and alloimmune priming following transplantation may indeed influence the specificity of the Treg required and the timing or frequency at which it needs to be administered. Here we review and discuss the relevance of antigen-specific regulation of alloreactivity by Tregs in experimental and clinical studies of tolerance and explore the concept of delivering an optimal Treg for the induction and maintenance phases of achieving transplantation tolerance.

Keywords: donor-specific, regulatory $\mathrm{T}$ cells, operational tolerance, indirect pathway, antigen-specific, direct pathway, linked suppression, alloantigen

\section{INTRODUCTION}

Transplantation presents a life-saving treatment for patients with end stage organ failure, however the success of this procedure is restricted by the recipient immune response directed against donor graft alloantigens and the clinical caveats associated with immunosuppressive drugs aimed at controlling this immune response. Current strategies for clinical management of transplant recipients using sustained immunosuppression do not fully prevent induction of the immunological processes which lead to graft rejection, namely chronic allograft failure, and as such the survival of a solid organ allograft is limited (Meier-Kriesche et al., 2004b; Lamb et al., 2010). Whilst early attrition rates for solid organ transplantation have significantly improved over the last few decades, attributed to reduced ischemia times, improved clinical procedures and patient care management, long term survival of allografts have remained relatively unchanged, requiring the majority of patients to have further organ transplants (MeierKriesche et al., 2004a; Lodhi et al., 2011). As this inevitably results in an escalating shortage of donor organs, there is a pressing need to develop an alternative method to control the alloimmune response which can establish stable long-term graft acceptance through induction of donor-specific immunological tolerance.

Transplantation tolerance can be defined as a state of immune unresponsiveness, downregulation or deviation of an immune response to an inflammatory situation or insult such as that generated by the recipient immune response following transplantation. Decades of experimental research have identified that mechanistic bases of immune tolerance may be through processes of deletion, anergy, antigen sequestration or immunological ignorance, and also the focus of this review, through processes of active regulation. Implementing mechanisms of immune regulation for tolerance induction are more desirable as an approach as it will, in principle, provide a mechanism which can adapt to the dynamic and evolving immune response post-transplantation. Amongst the $\mathrm{T}$ cell subsets with immunomodulatory properties, the regulatory roles of thymus derived $\mathrm{CD} 4{ }^{+} \mathrm{CD} 25^{\text {high }} \mathrm{FoxP} 3^{+}$ naturally occurring regulatory $\mathrm{T}$ cells (Tregs) have been recognized for many years and substantial research efforts have sought to exploit their suppressive functions to deliver a tolerogenic cell therapy for transplantation (Hippen et al., 2011; Lombardi et al., 2011). This transition to the clinic has been facilitated by the significant progress made over the last 5 years in identification of further markers to delineate stable suppressive Treg subsets, such as CD45RA, CD161, CCR6, and low expression of IL-7 receptor $\alpha$ chain CD127, in addition to previously described expression of transcription factor Forkhead box p3 (FoxP3), CTLA-4, GITR, and CD62L (Liu et al., 2006; Miyara et al., 2009). Recently, their development as a cell therapy has been translated to clinical hematopoietic stem cell transplantation settings (Sakaguchi, 2004; Sagoo et al., 2008) and use in phase I and 
II clinical trials are showing tentative yet encouraging results in terms of both safety and efficacy (Brunstein et al., 2011; Di Ianni et al., 2011). The main therapeutic approach currently in use is to infuse freshly isolated or ex vivo polyclonally expanded Tregs into graft recipients with an aim to provide a more favorable in vivo balance of $\mathrm{T}$ effector cells to regulatory cells. However, our current understanding of the alloimmune response suggests that regulation of donor-reactive immunity primed by specific pathways of alloantigen-presentation following transplantation may be central to achieving long-term or indefinite graft survival (Nepom et al., 2011; Wood et al., 2011). This concept is now being supported by mounting experimental evidence from basic and clinical studies, which indicate that the next stage in optimizing translation of Tregs to solid organ transplantation will be through the refinement and delivery of donor alloantigen-specific Treg therapy.

This review article discusses the relevance of antigen-specific regulation of alloreactivity by Tregs and explores the concept and goal of defining an optimal Treg for the prevention of transplant rejection and induction of organ transplant tolerance. We identify the main features of the immune response which Tregs need to control by firstly reviewing evidence for the induction and temporal pattern of the alloimmune response, in terms of alloantigen presentation and allopriming following transplantation, and the resulting effector mechanisms of graft rejection. We then review evidence for the association of Tregs and Tregmediated donor-specific immune regulation in clinical transplantation with particular focus on data emerging from the study of operationally tolerant transplant recipients. After reviewing these findings we then discuss the mechanistic bases of tolerance induction by antigen-specific Tregs, and the requirements of an optimized Treg to improve the success of this approach for the induction and maintenance phases of achieving donor-specific tolerance.

\section{THE ALLOIMMUNE RESPONSE}

Induction of the adaptive immune response to an allograft begins with recognition of alloantigen by recipient $T$ cells which is now well characterized and known to occur through three main processes known as the direct, the indirect, and the semi-direct pathways of antigen presentation. The relative contributions of the direct and indirect pathways of alloantigen presentation toward graft rejection have been reviewed in detail elsewhere (Afzali et al., 2007; Gokmen et al., 2008), however the key questions we examine here are whether the differential activity of these alloantigen presentation pathways are associated with transplantation tolerance, and whether their activity is modulated though a process of active regulation which may otherwise be achievable using alloantigen-specific Treg therapy. Our understanding of factors such as the temporal activity and intensity of alloantigen presentation pathway activity, and resulting alloimmune priming following transplantation is integral to identifying the specificity of the Treg required and the time or frequency at which it needs to be administered to deliver an optimized and targeted therapeutic. We therefore begin by providing a brief updated overview of allorecognition, which is summarized in Figure 1A.

\section{PATHWAYS OF ALLOANTIGEN PRESENTATION}

The direct pathway of alloantigen presentation is so named as intact allogeneic major histocompatibility complex (MHC) molecules expressed by donor allograft derived cells are directly presented to recipient T cells. The most potent driver of $\mathrm{CD} 4^{+}$ and $\mathrm{CD}^{+} \mathrm{T}$ cell responses with specificity for alloantigen presented by the direct pathway is through the migration of donor antigen-presenting cells (APCs) from the allograft to the secondary lymphoid organs (Larsen et al., 1990). Here, donor MHC alloantigens are recognized by alloreactive $\mathrm{T}$ cells which are estimated to be of a relatively high endogenous frequency of between 1:100 and 1:100,000 T cells in humans (Hornick et al., 1998; Game et al., 2003; Benitez and Najafian, 2008), and even higher (1:10) in mouse (Suchin et al., 2001). As such, they are able to elicit a vigorous inflammatory $\mathrm{T}$ cell response toward the allograft resulting in early or acute rejection. This pre-existing population of $\mathrm{T}$ cells with specificity for the direct pathway is a long-standing conundrum in immunology, as recipient $\mathrm{T}$ cell recognition of foreign $\mathrm{MHC}$ molecules which have not previously been encountered in the thymus violates the rules of self-MHC restriction therefore, direct allorecognition may be attributed to cross-reactivity, namely the ability of self-MHC restricted $\mathrm{T}$ cell $\mathrm{T}$ cell receptors (TCRs) to recognize polymorphic residues on foreign MHC through structural similarities between donor and recipient MHC molecules (Lombardi et al., 1991; Lechler et al., 1992), although evidence exists which favors the hypothesis that the peptide primarily determines the diversity of the $\mathrm{T}$ cell response (Weber et al., 1995). The latter may also explain the occurrence of alloreactivity when donor and recipient MHC are structurally dissimilar. Based on the nature of direct pathway allorecognition (Gras et al., 2011), the direct pathway alloreactive $\mathrm{T}$ cell compartment is predicted to arise equally from within either naive $\mathrm{CD}_{45 \mathrm{RA}^{+}}$or memory $\mathrm{CD} 45 \mathrm{RO}^{+} \mathrm{T}$ cell compartments and is polyclonal in nature (Merkenschlager and Beverley, 1989; Lombardi et al., 1990). Macedo et al. have recently provided further evidence for this by studying effector functions (IFN $\gamma$ production), proliferation and precursor frequencies in isolated human $\mathrm{CD}^{+}$and $\mathrm{CD}^{+}$naive and central/effector memory $\mathrm{T}$ cell subsets, in response to stimulation with allogeneic peripheral blood mononuclear cells (PBMCs; Macedo et al., 2009). These characteristics have particular relevance to the development and application of effective immunosuppressive approaches to control the direct alloresponse. A lesser described stimulator of the direct alloresponse is that of the presentation of allogeneic MHC by non-professional antigen presenting cells such as activated donor endothelium or epithelium within donor tissue. While several studies have shown this may be able to stimulate $T$ cells requiring lower costimulatory signal thresholds, such as memory $\mathrm{T}$ cells (London et al., 2000; Berard and Tough, 2002), other work has shown this may not necessarily result in productive stimulation of alloreactivity (Marelli-Berg et al., 1996).

The indirect pathway of alloantigen presentation occurs when recipient bone-marrow derived APCs capture, process, and present allogeneic $\mathrm{MHC}$ determinates to recipient $\mathrm{T}$ cells. In this pathway, alloantigen may be acquired from the circulation from shed donor graft material, collected by recipient APCs trafficking through the allograft, or through the phagocytosis of 
A

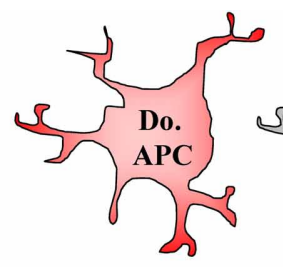

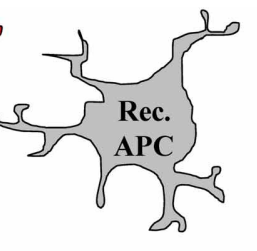

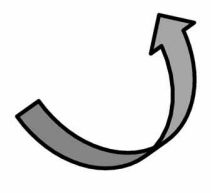

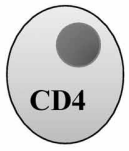

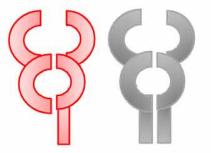

\section{Donor APC Recipient APC T cell Help Recipient T cell HLA molecules \\ Donor APC Recipient APC T cell Help Recipient T cell HLA molecules}

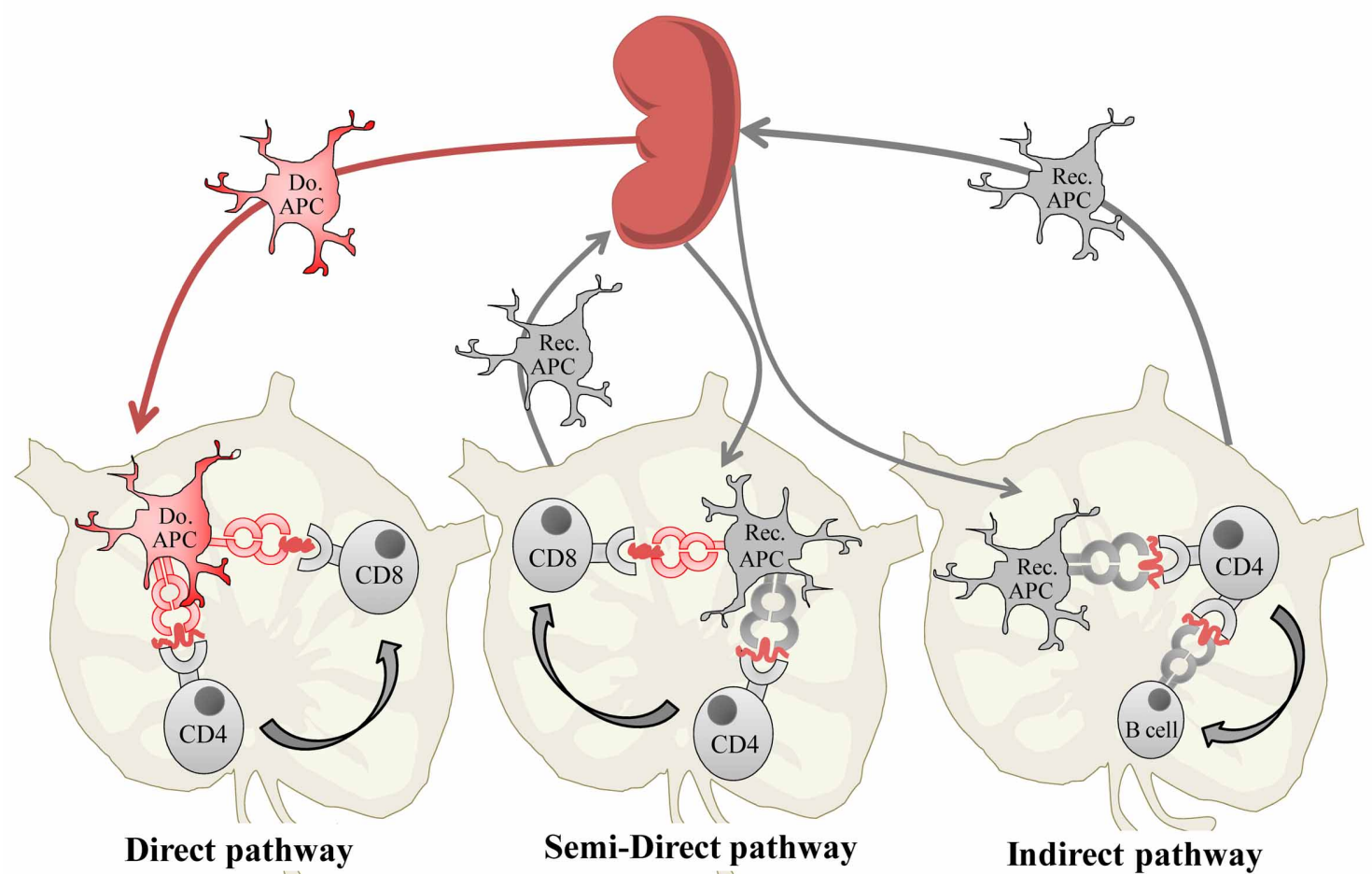

B

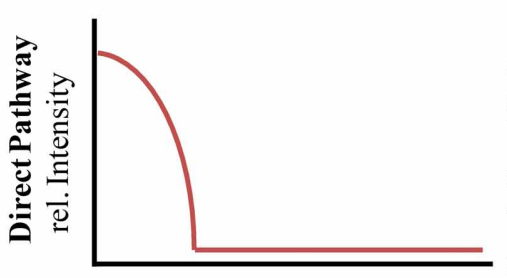

Duration post-Tx

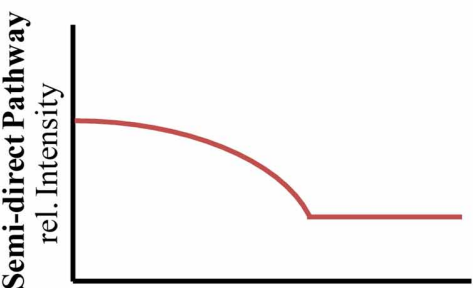

Duration post-Tx

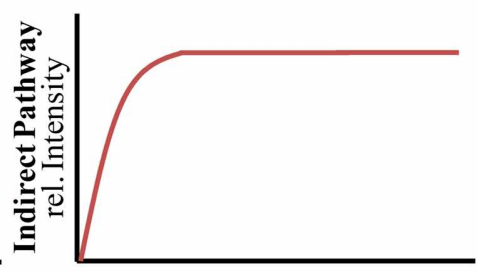

Duration post-Tx

FIGURE 1 | (A) Alloantigen presentation via the direct, semi-direct and indirect pathways following organ transplantation, and (B) the relative intensity of each antigen-presentation pathway during the post-transplantation (post-Tx) period.

donor APCs that have migrated to the draining lymph nodes. As stimulation of this pathway is dependent upon the limitless supply of graft-derived antigens, it is initiated immediately posttransplantation and sustained throughout the life of the graft. The pre-existing endogenous frequency of alloreactive $T$ cells with specificity for the indirect pathway is detected to be much lower than that of the direct pathway, with a range in frequency of 1:100,000-1:1,000,000 T cells (Hornick et al., 2000; Baker et al., 2001a). Although this antigen presentation pathway becomes active immediately following transplantation, the initially low frequency indirect alloresponse is not generally considered to be of sufficient intensity to be the main stimulus of early or acute graft rejection in a clinical setting, although in some experimental models of graft rejection described later it has been shown to induce acute rejection. Instead, the continuous and progressive priming of the immune response to indirectly presented alloantigens is thought to gradually amplify effector $\mathrm{T}$ cell responses with indirect allospecificity to culminate in chronic immune-mediated 
rejection (Vella et al., 1997; Hornick et al., 2000; Baker et al., 2001a; Gokmen et al., 2008).

The semi-direct pathway is the most recently described pathway of antigen presentation and occurs when intact allogeneic MHC:peptide complexes are captured from donor cell membranes by recipient APCs and incorporated, with maintenance of sufficient molecular and structural integrity to prime recipient $\mathrm{T}$ cell alloresponses to the direct pathway (Herrera et al., 2004; Smyth et al., 2006; Riond et al., 2007; Smyth et al., 2007). There is, therefore, the potential for any given APC to simultaneously present alloantigen both via the direct and indirect pathways. In addition to dendritic cells (DCs) and macrophages, a significant proportion of B lymphocytes have also been shown to acquire allogeneic MHC molecules, and this process is also now known to be bidirectional whereby cells of donor origin can also capture and present recipient derived MHC complexes (Brown et al., 2008, 2011).

The ability of the semi-direct pathway to link both the direct and indirect pathways of alloimmune priming of $\mathrm{T}$ cell responses may simplify the matter of selecting an appropriate allospecific Treg to regulate the alloreponse by permitting linked or bystander suppression by allospecific Treg, a concept which we return to later. The semi-direct pathway, therefore, illustrates that neither pathway of alloantigen presentation is mutually exclusive post-transplantation. This is further revealed by studying the mechanisms, kinetics, and altering intensity of the alloimmune response.

\section{DYNAMICS OF ALLOANTIGEN PRESENTATION}

An important aspect of administering optimized donor-specific Treg cell therapy is to determine when to deliver their immmunoregulatory effects in vivo. A sensible presumption would be to apply them in advance of or simultaneously to the induction of alloantigen presentation pathway activities, to counteract the allopriming effect. Our understanding of the dynamics of the alloimmune response is provided in part by studying the survival and trafficking of donor and recipient APCs in vivo but is also revealed more directly by experimental and clinical studies reporting on the duration and intensity of both direct and indirect pathway primed $\mathrm{T}$ cell alloresponses following transplantation (Figure 1B).

The contribution of alloimmune priming by the direct pathway was first demonstrated by seminal experiments examining the effects of donor allograft passenger APCs on kidney allograft survival (Lechler and Batchelor, 1982a). Several studies have since confirmed that abrogation of the direct pathway typically results in a prolongation of graft survival rather than achieving an outcome of true tolerance (Garrod et al., 2010; Fernandes et al., 2011; Gupta et al., 2011), suggesting it is not the only driver of graft rejection. Due to the clearance of donor passenger APCs, the direct alloresponse it is thought to be a relatively short-lived (Lechler and Batchelor, 1982a,b; Hornick et al., 1998), allowing indirect allospecific $\mathrm{T}$ effectors responses to dominate. Clearance of donor APCs has recently been shown to be a highly efficient process mediated by recipient cytotoxic lymphocytes (CTLs; Laffont et al., 2006) and natural killer (NK) cell killing, the latter of which can efficiently remove allogeneic donor APC introduced by adoptive transfer or by a skin allograft within hours post-transplantation, to limit any consequent priming of direct pathway alloreactive effector $\mathrm{T}$ cell responses (Laffont et al., 2008; Garrod et al., 2010). However, the discovery of the semi-direct pathway implies that the direct pathway is not completely inhibited by this process. Therefore, these data clearly suggest that targeted approaches to control both the direct pathway, perpetuated by the semi-direct pathway, and the indirect pathway may be better able to deliver tolerance induction.

Recent data supports this view by providing evidence of the presentation of donor alloantigen by the semi-direct pathway for prolonged periods post-transplantation. In a rat model of complete MHC mismatched (LEW $\rightarrow$ BN) liver transplantation, Toyokawa et al. were able to detect donor MHC Class II L21-6 ${ }^{+}$ $\mathrm{CD}_{11 \mathrm{c}^{+}}$cells within allografted tissues up to 200 days posttransplantation (Toyokawa et al., 2008), but surprisingly found they disappeared much earlier when grafts were performed into recipient animals pre-depleted of macrophage and DC compartments using clodronate liposomes. While the authors speculated that this early loss of cells expressing donor MHC class II may be due to lack of a survival advantage conferred by recipient APCs through microenvironment conditioning, other studies of surface MHC transfer suggest that the prolonged persistence of donor MHC expression of CD11 $\mathrm{c}^{+}$cells is more likely to be due to the semi-direct pathway. In a mouse kidney graft model of spontaneous tolerance (DBA-2 $\rightarrow$ C57BL/6), Brown et al. were able to demonstrate activity of the semi-direct pathway as early as 8 days post-transplantation by counter-staining lymphoid tissues for both recipient and donor MHC class II expression (Brown et al., 2008). They were able to detect a surprisingly high proportion of APCs with I-A ${ }^{\mathrm{d}}$ (DBA-2 MHC class II) and I-A ${ }^{\mathrm{b}}$ (C57BL/6 MHC Class II) expression ( $30 \%)$, which remained detectable for extended periods of over 80 days post-transplantation. In the study by Tokoyawa et al., the semi-direct pathway is, therefore, a more likely explanation for prolonged direct pathway donor alloantigen presentation, particularly as in this same study they also detected upregulation of MHC class II expression by donor allograft epithelial and endothelial cells during inflammation, which could have provided a continuous source of donor alloantigen. This would however need to be confirmed by staining for both donor and recipient MHC expression.

Although $\mathrm{CD}^{+} \mathrm{T}$ cells with direct allospecificity are well placed to provide help to alloreactive $\mathrm{CD} 8^{+} \mathrm{T}$ cells, through the likely 3-cell clusters formed between direct alloreactive $\mathrm{CD} 4^{+}$and $\mathrm{CD}^{+} \mathrm{T}$ cells interacting with a donor-derived APC expressing both allogeneic MHC class I and II, there must be an alternative provision of help for $\mathrm{CD}^{+} \mathrm{T}$ cells, as otherwise the clearance of donor passenger APCs would result in a parallel reduction of alloreactive $\mathrm{CD}^{+}{ }^{+} \mathrm{CTL}$ responses. This long-standing conundrum is partly resolved by demonstration of a helper $\mathrm{T}$ cellindependent mechanism of $\mathrm{CD}^{+} \mathrm{T}$ cell alloactivation (Jones et al., 2006) and partly by the provision of $\mathrm{T}$ cell help via $\mathrm{CD} 4^{+} \mathrm{T}$ cells with indirect allospecificity (Lee et al., 1994). Precisely how an indirect alloreactive $\mathrm{CD} 4^{+} \mathrm{T}$ cell with self-MHC restriction would encounter a direct allospecific $\mathrm{CD} 8^{+} \mathrm{T}$ cell interacting with a cell expressing intact allogeneic Class I MHC, is resolved by the semi-direct pathway where an APC can present both allogeneic 
class I and processed allopeptides in the context of Class II self-MHC. Fischer et al. have shown that combining tolerogenic conditioning of recipient murine DCs through Rapamycin drug treatment, with DC capture of intact MHC Class I from allogeneic cell lysates, results in alloantigen presentation via the semi-direct pathway, and drives regulation of direct alloreactive $\mathrm{CD}^{+} \mathrm{T}$ cell responses in vitro and in vivo. This study indicates the potential of this pathway in mediating effective immune regulation as well as alloimmune priming (Fischer et al., 2011). Whereas presentation of donor-derived MHC Class I via the semi-direct pathway may remain sustained, as stable graft function develops through sustained immunosuppression or developing immune regulatory processes, presentation of MHC Class II via this pathway may play a lesser role during the post-transplant period as it's sources and activation-induced expression subside with diminution of the inflammatory microenvironment.

Combined, these data shed an alternative view on the role of donor APCs in priming the alloresponse early post transplantation, where their main effect may also be through the provision of an early and high density source of donor antigen to prime the indirect and semi-direct pathways. Activity of these two pathways has recently been demonstrated on a more direct visual basis by the detection of Yae (antibody with specificity for Class I H2-K $\mathrm{K}^{\mathrm{d}}$ peptide presented by I-A $\mathrm{A}^{\mathrm{b}}$ complex) and MHC class II I-A $\mathrm{A}^{\mathrm{d}}$ double positive APCs within lymphoid tissue of $\mathrm{C} 57 \mathrm{BL} / 6\left(\mathrm{H} 2-\mathrm{K}^{\mathrm{b}}\right)$ mice that have received a BALB/c $\left(\mathrm{H} 2-\mathrm{K}^{\mathrm{d}}\right)$ heart graft, demonstrating the capacity of recipient APCs to simultaneously prime both direct and indirect T cell alloresponses (Brown et al., 2011). The predominance of alloantigen presentation via the indirect pathway early in the post-transplantation period in addition to its more usual role in chronic rejection is now becoming a better established phenomenon.

In this respect, the contribution of the indirect pathway toward allograft rejection has been firmly established by studies using donor grafts from $\mathrm{MHC}$ class $\mathrm{II}^{-/-}$mice, where rejection can be efficiently induced in the complete absence of direct pathway presentation of alloantigen (Auchincloss et al., 1993; Honjo et al., 2004). Graft rejection dependent on indirect pathway presentation of alloantigens or minor antigens is also now well described (Jurcevic et al., 2001; Sims et al., 2001; Smith et al., 2001; Fernandes et al., 2011), and can occur with little or no change (Garrod et al., 2010; Gupta et al., 2011) in the kinetics of graft rejection compared to when the direct pathway is also active. In support of these findings Brennan et al. have demonstrated the efficiency of the indirect pathway compared to the direct pathway of alloantigen presentation (Brennan et al., 2009). This study co-transferred murine CD4 and CD8 T cells with TCR transgenes conferring specificity for either the direct pathway $\left(\mathrm{I}-\mathrm{A}^{\mathrm{d}}\right.$ and $\mathrm{H} 2-\mathrm{K}^{\mathrm{d}}$, respectively), or the indirect pathway $\left(\mathrm{H} 2-\mathrm{K}^{\mathrm{d}}: \mathrm{I}-\mathrm{A}^{\mathrm{b}}\right.$ complex) into $\mathrm{C} 57 \mathrm{BL} / 6$ mice $\left(\mathrm{I}-\mathrm{A}^{\mathrm{b}}\right)$ which were then challenged with $\mathrm{BALB} / \mathrm{c}\left(\mathrm{I}-\mathrm{A}^{\mathrm{d}}\right)$ heart or skin grafts. On adoptive transfer, $\mathrm{T}$ cells with indirect allospecificity proliferated with much more rapid kinetics compared to $\mathrm{T}$ cells with direct specificity, which was also reflected by endogenous alloreactive $\mathrm{T}$ cell populations. Using a murine transplant model Gupta et al. were able to measure the kinetics of alloantigen presentation though the direct or indirect pathways by grafting skin from a BALB/c or CB6F1
(C57BL/6 × BALB/c F1) mouse onto a C57BL/6.TEa.Rag2-/recipient mouse, in which the $\mathrm{T}$ cells have indirect specificity for I-E alpha peptide presented by C57BL/6 MHC class II I-A ${ }^{\mathrm{b}}$ (Gupta et al., 2011). They found that on indirect presentation alone, where BALB/c donor alloantigens must first be processed via the indirect pathway for presentation to TEa T cells, rejection was delayed by 6 days compared to direct antigen presentation (endogenous expression of I-E $\alpha: I-A^{b}$ complex by CB6F1 DCs), suggesting this short delay was caused by the time lag required for antigen processing and presentation by the recipient DCs before subsequent $\mathrm{T}$ cell proliferation. Although these findings concur with the concept that late graft rejection is associated with a gradually priming and maintenance of the indirect pathway, they fundamentally differ from the findings by Brennan et al., however these differences may be attributed to the allograft model or TCR transgenic T cells used, suggesting although these models are ideal for dissecting mechanistic basis of alloimmune priming, examining clinical data may be more informative for developing practical therapeutic strategies for intervention.

\section{IMPLICATIONS FOR DONOR-SPECIFIC TREG THERAPY}

The experimental findings described above underpin two main features of alloimmunity, firstly that the indirect pathway is active immediately following transplantation and secondly that the direct pathway can contribute toward the maintenance of the indirect pathway and may be active later in the posttransplantation period through the semi-direct pathway. It may, therefore, be tempting to speculate that Treg therapy would be best applied either pre-transplantation or at the time of transplantation to prevent any initial priming of memory alloreactive $\mathrm{T}$ cell responses, perhaps through modulation of APC activities (Misra et al., 2004; Mahnke et al., 2007; Herman et al., 2012). However, several recent studies have demonstrated that maintenance of alloantigen presentation throughout the lifetime of the organ transplant is also key to achieving tolerance, particularly so when mechanistically Tregs are involved.

Chiffoleau et al. have shown that a rat model of donorspecific heart transplant tolerance (fully MHC mismatched LEW.1W $\rightarrow$ LEW.1A) is associated with an expansion of splenic Tregs. In parallel, the study detected the persistence and even proliferation (possibly a consequence of the deoxyspergualin analogue tolerising protocol used) of donor DCs for over 100 days post-transplantation, which were restricted to the allografted tissue, achieving a localized tissue chimerism (Chiffoleau et al., 2002). Interestingly, this group found that pre-depletion of donor APCs from the heart allograft prior to transplantation by cyclophosphamide treatment, resulted in a reduction in splenic Tregs and abrogation of the tolerogenic effect. In vitro analysis further confirmed that $\mathrm{CD} 4{ }^{+} \mathrm{T}$ cells from tolerised animals showed direct pathway donor-specific suppressive activity. Therefore, using this particular tolerising protocol, alloantigen presentation via the direct pathway was critical for induction of transplant tolerance and generation of donor-specific Tregs, suggesting this may be mechanistically a critical contributor toward the successful approach of using mixed-chimerism to induce tolerance to a solid organ transplant (Ko et al., 1999b; Andreola et al., 2011). 
Several other studies have also shown that persistent presentation of donor alloantigen is also essential for the maintenance of solid organ transplant tolerance in rodent models. Hamano et al. showed that stable tolerance of a murine allogeneic heart graft induced by anti-CD4 monoclonal antibodies and donorspecific transfusion (DST) was lost when second donor-matched hearts were transplanted 200 days after the removal of the primary hearts, that is, once all donor-alloantigen had been cleared from the recipient mouse (Hamano et al., 1996). This implies that unlike the study by Chiffoleau et al., donor-microchimerism through the survival of donor APCs is not essential for maintenance of tolerance (Ko et al., 1999a), but rather that activation of semi-direct or indirect pathways of alloantigen presentation, by any source of alloantigen, may be more critical. This theory corresponds with evidence of the requirement of continuous presence of donor alloantigens for Treg survival in allograft tolerance models (Scully et al., 1994; Chen et al., 1996; Hamano et al., 1996). Two recent studies add further support to this concept by using miniature swine models of allotransplantation to study the stability of tolerance and the contribution of alloantigen presentation via the indirect pathway toward maintenance of tolerance (Okumi et al., 2008; Weiss et al., 2009). Okumi et al. were able to demonstrate that once a primary MHC class I mismatched tolerised kidney allograft had been removed and all endogenous donor alloantigen had been cleared, animals could be sensitized to reject a second identical donor graft by injection of donor MHC Class I peptides. However, immunization of long-term tolerised animals with donor MHC Class I peptides did not lead to the rejection of a primary graft, indicating that alloantigen presentation via the indirect pathway could both break tolerance and be crucial in the induction and maintenance of tolerance.

The relevance of these studies toward developing Treg therapy is challenging to conclude, largely because of the intricacies and variation within each experimental model, with respect to transgenic mice used or tolerising protocols applied, which may or not be associated with Treg mediated regulatory processes. What can be deduced is that for induction of long-term stable graft tolerance, active presentation of alloantigen is required, which over the life-time of an allograft will be mediated primarily by the indirect pathway. Sustained alloantigen presentation may function by promoting antigen-driven activation, expansion, or survival of in vivo induced or adoptively transferred donor-specific Tregs (Walker et al., 2003; Sanchez-Fueyo et al., 2006), which may in turn stimulate other alloantigen-specific immune regulatory processes, a concept which is explored in more detail in the following section.

\section{DONOR-SPECIFIC TREG CONTROL OF ALLOIMMUNE RESPONSES FOLLOWING TRANSPLANTATION}

As well as their critical role in immune homeostasis and regulation of autoimmunity (Sakaguchi and Sakaguchi, 2005), Tregs can function to regulate the alloimmune response through a number of mechanisms which include release of immunosuppressive cytokines, modulation of APC and endothelial functions, or direct suppression of $\mathrm{CD}^{+}$and $\mathrm{CD}^{+} \mathrm{T}$ effector cells to summarize but a few (Shevach, 2009). Here we examine the requirements of Tregs to control several important aspects of the alloimmune effector response, outlining where the advantages of donor-specific Treg use for immune regulation may lie.

\section{DONOR-SPECIFIC TREGS DELIVER LOCALISED IMMUNE REGULATION}

Targeting the immunoregulatory properties of Tregs to the sites of anti-donor effector responses would circumvent the issue of the relative paucity of Tregs, which would otherwise limit their efficacy in vivo. The effector arm of the indirect alloresponse is broad and can occur at remote sites to the donor allograft as discussed later, however as indirect allospecific $\mathrm{T}$ cells are unable to recognize the tissue allograft directly to mediate direct lysis or cell mediated immunity, that is in a completely MHC mismatched donor recipient setting, they would only potentially be able to directly damage the allograft by bystander killing. In contrast, direct allospecific $\mathrm{T}$ cells accumulate and act at the graft site through recognition of expressed intact MHC. An immediate advantage of transferring Tregs with direct pathway alloantigen-specificity would, therefore, be that they would naturally localize to the equivalent site of allospecific effector $\mathrm{T}$ cell priming to mediate their regulatory effects. Indeed, Tregs have been described to specifically accumulate at sites of alloantigen sources, alloimmune effector priming or target activity, to establish a state of local immune privilege (Golshayan et al., 2007, 2009; Dijke et al., 2008). In experimental models of allograft tolerance, Tregs with the ability to transfer tolerance to naive recipients have also been detected within draining lymph nodes and also donor allografted tissue (Graca et al., 2002). In a recent study by Heslan et al., analysis of $\mathrm{T}$ cells isolated from tolerised allografts, also capable of transferring donor-specific tolerance to naive recipients, showed skewed TCR V $\beta$ repertoires which may reflect an accumulation of oligioclonal donor alloantigen specific regulatory T cells (Heslan et al., 2005). What many studies have been unable to demonstrate is whether Tregs are generated elsewhere and then migrate to the graft site from the periphery or whether they are induced within an allografted tissue itself. However these studies do highlight the major advantage offered by a therapeutic strategy to adoptively transfer donor-specific Tregs into transplant recipients, by allowing their immunomodulatory functions to be readily concentrated at the source of their cognate alloantigen expression and subsequent immune activation (Golshayan et al., 2007). We have recently demonstrated that transfer of human Tregs selected for direct pathway donor allospecificity are more effective at preventing rejection of a human skin graft in a humanized mouse xenograft model, compared to polyclonal Tregs (Sagoo et al., 2011). On studying early trafficking of adoptively transferred human Tregs (3 days), similar numbers of both allospecific and polyclonal Tregs were recruited to skin allografts, although a higher proportion of allospecific Tregs were found to be in contact with skin resident alloantigen (HLA-DR ${ }^{+}$) bearing donor cells. These data allow speculation that donor-specific Treg mediated suppression occurs primarily at sites of alloantigen expression and effector target tissue, and possibly acts through early interaction and modulation of APC function and effector cell recruitment, as implicated by other in vitro and in vivo studies (Golshayan et al., 2009; Herman et al., 2012). Analysis at later time 
points ( 4 weeks) showed significantly higher numbers of allospecific Tregs were present in allografted tissues, which concurs with the hypothesis that antigen-driven expansion or survival of allospecific Tregs had occurred (Walker et al., 2003; SanchezFueyo et al., 2006), and which may contribute to the improved efficacy of donor-specific Tregs in this model. These findings also resonate with functional differences detected between antigenspecific and polyclonal Tregs in other murine models of tolerance induction (Golshayan et al., 2007; Joffre et al., 2008; Tsang et al., 2009). In contrast, considerable success using polyclonal Tregs in preventing experimental graft versus host disease (GvHD) has also been demonstrated (Edinger et al., 2003; Trenado et al., 2003). The disparity between the relative efficacy of polyclonal Tregs in these transplantation settings may again be related to the localization of alloreactive responses, which during GvHD is more systemic and, therefore, equally amenable for polyclonal Treg mediated regulation.

The frequency and distribution of Tregs have also been studied in the context of clinical transplantation both in observational/association studies, and also in several studies extending to cellular function analysis of Treg mediated suppression, the latter of which is discussed later. As summarized in Table 1 (Columns A and C), several studies examining clinically stable allograft recipients, those undergoing rejection, and healthy "control" individuals, in general find no consistent differences in the frequencies of peripheral blood circulating levels of Tregs. Shan et al. (2011) have recently compiled a more comprehensive review of over 20 observational clinical studies which have examined the association of detected human Tregs with liver, heart, lung, and kidney allograft outcome. Their meta-analysis shows that elevated intra-graft Tregs detected by relative increase in FoxP3 ${ }^{+}$ cells or quantitative mRNA expression expression could, in general, be positively correlated with improved graft function or outcome, whereas numbers of circulating Tregs, the most common method of analysis, could not be consistently correlated with outcome. This finding again reinforces the concept of targeting Tregs to the correct in vivo site for optimal alloimmune suppression. This is further supported by a study by Bestard et al. which found that renal transplant patients whom developed $\mathrm{T}$ cell hyporesponsiveness toward their donor after transplantation also had significantly higher levels of $\mathrm{CD}^{+}{ }^{+} \mathrm{FoxP} 3^{+}$cells within their allograft infiltrates compared to patients whom showed donorreactivity (Bestard et al., 2007). Similar observations of elevated foxp 3 mRNA expression in allograft biopsies have also been made in combined bone marrow transplant (BMT) and kidney allograft patients whom develop operational tolerance (Kawai et al., 2008).

Indeed, studies of human Tregs in patients with operational tolerance are more revealing and in general bode well for cell therapy approaches aiming to increase in vivo Treg numbers (Table 2, Column A). Several studies have detected increases in percentages of $\mathrm{CD} 4^{+} \mathrm{CD} 25^{+}$Tregs as a proportion of total $\mathrm{CD} 4^{+} \mathrm{T}$ cells and also absolute numbers of Tregs in peripheral blood circulation in tolerant liver transplant recipients compared to healthy controls, patients with stable graft function whom are maintained on immunosuppressive drugs, and patients with active immunemediated graft rejection (Li et al., 2004, 2008; Martinez-Llordella et al., 2007; Pons et al., 2008). Li et al. have further confirmed that higher percentages of FoxP3 ${ }^{+}$cells are also detected in biopsy material from some tolerant liver transplant patients ( $\mathrm{Li}$ et al., 2008). More recently, expansion of in vivo numbers of circulating Tregs has been strongly linked to immunosuppression withdrawal protocols and establishment of tolerance in cohorts of liver transplant recipients (Nafady-Hego et al., 2010). The association of Tregs with operational tolerance in other organs such as kidney is not as consistent, with the majority of studies observing that tolerant patients do not have higher percentages or absolute number of Tregs in circulation compared to other patient groups described (Louis et al., 2006; Braudeau et al., 2007; Newell et al., 2010; Sagoo et al., 2010). In two recent studies examining the largest cohorts of renal transplant patients with established long-term operational tolerance to date, neither study detected expansion of $\mathrm{CD} 4{ }^{+} \mathrm{CD} 25^{\text {high }}$ Tregs in peripheral blood (Newell et al., 2010; Sagoo et al., 2010). While all clinical studies of renal transplant recipients described in Table 2 identified no differences in percentages or numbers of circulatory Tregs between tolerant individuals and healthy control subjects, two studies did detect a significant reduction of Tregs in patients with chronic graft rejection (Louis et al., 2006; Braudeau et al., 2007). This observation suggests that tolerance may not be directly related to a numerical advantage in peripheral Tregs, more rather that tolerant individuals may maintain Tregs numbers similar to that of healthy individuals, whereas reduced Treg numbers may be associated with poor graft outcome. This difference may of course be a consequence of patients whom go on to develop chronic rejection having lower pre-transplant frequencies of Tregs, which is an important question that can be examined by the prospective and longitudinal immune monitoring of transplant recipients. Reviewing the clinical studies of operational tolerance summarized in Table 2 highlights an emerging dichotomy between liver and kidney transplantation and the differing role of circulatory Tregs within each organ transplant setting. This deserves further investigation and warrants deeper phenotypic and functional analysis, particularly in view of some divergence in genetic profiles of immunological tolerance that have recently been identified between these two organs (Martinez-Llordella et al., 2008; Perucha et al., 2011; Sawitzki et al., 2011).

As suggested earlier, analysis of Treg frequencies in peripheral blood may be entirely perfunctory, and may not be indicative of allograft infiltrating Tregs or active mechanisms of regulation taking place within the tissue. Interestingly, despite observing no differences in peripheral blood Treg numbers between patient study groups, by studying urine sediment, which is anticipated to be reflective of the cellular composition of the kidney allograft, Newel et al. were able to detect higher foxp3 expression by operationally tolerant patients compared to healthy control subjects, highlighting the subtleties of immunological monitoring that need to be considered when interpreting observations in clinical transplantation (Newell et al., 2010). Although intragraft Treg composition is challenging to measure directly, an intermediate method of assessing the role of Tregs and immune regulation in tolerance is through the detection of donor-specific hyporesponsiveness by allograft recipients. 


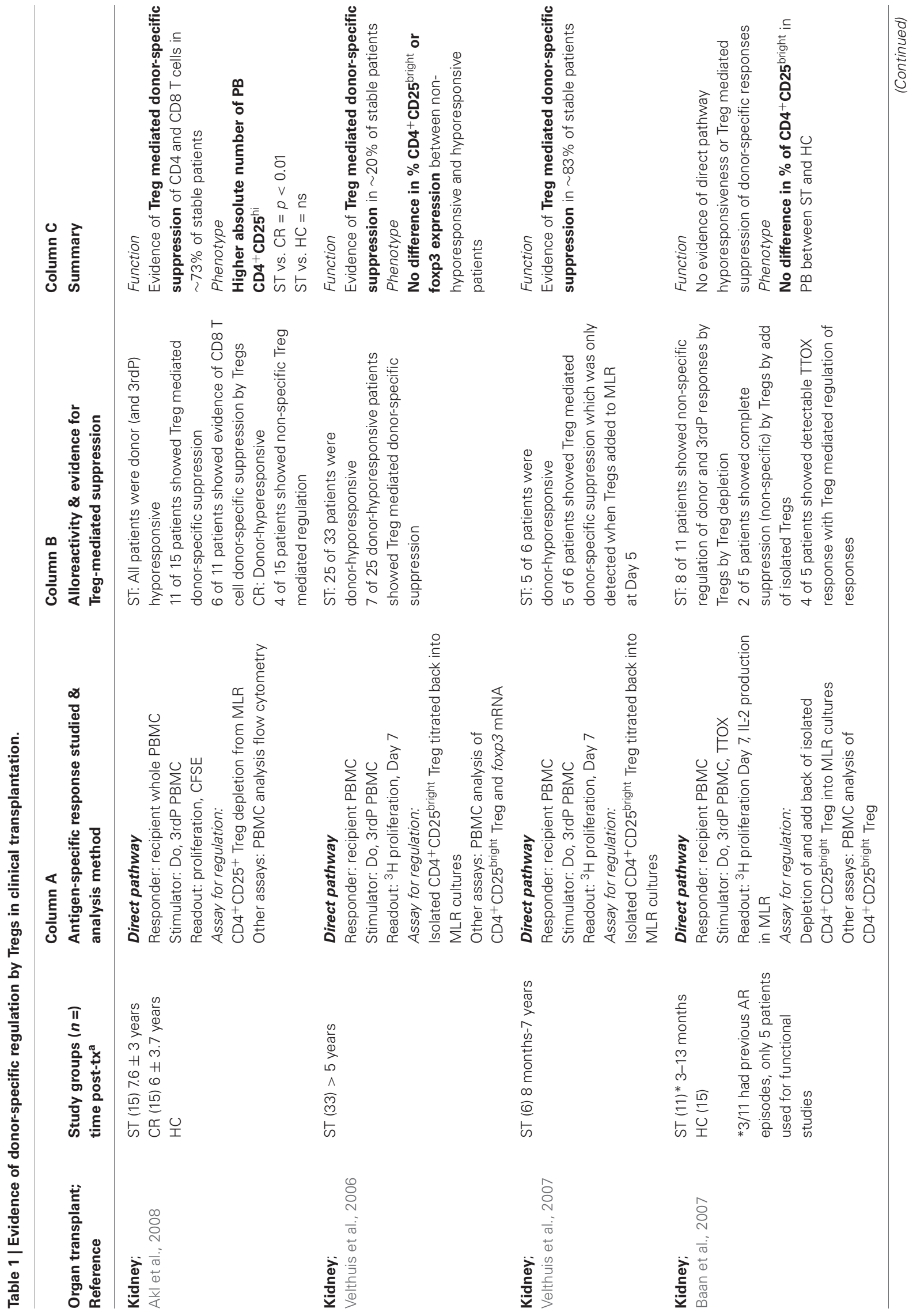




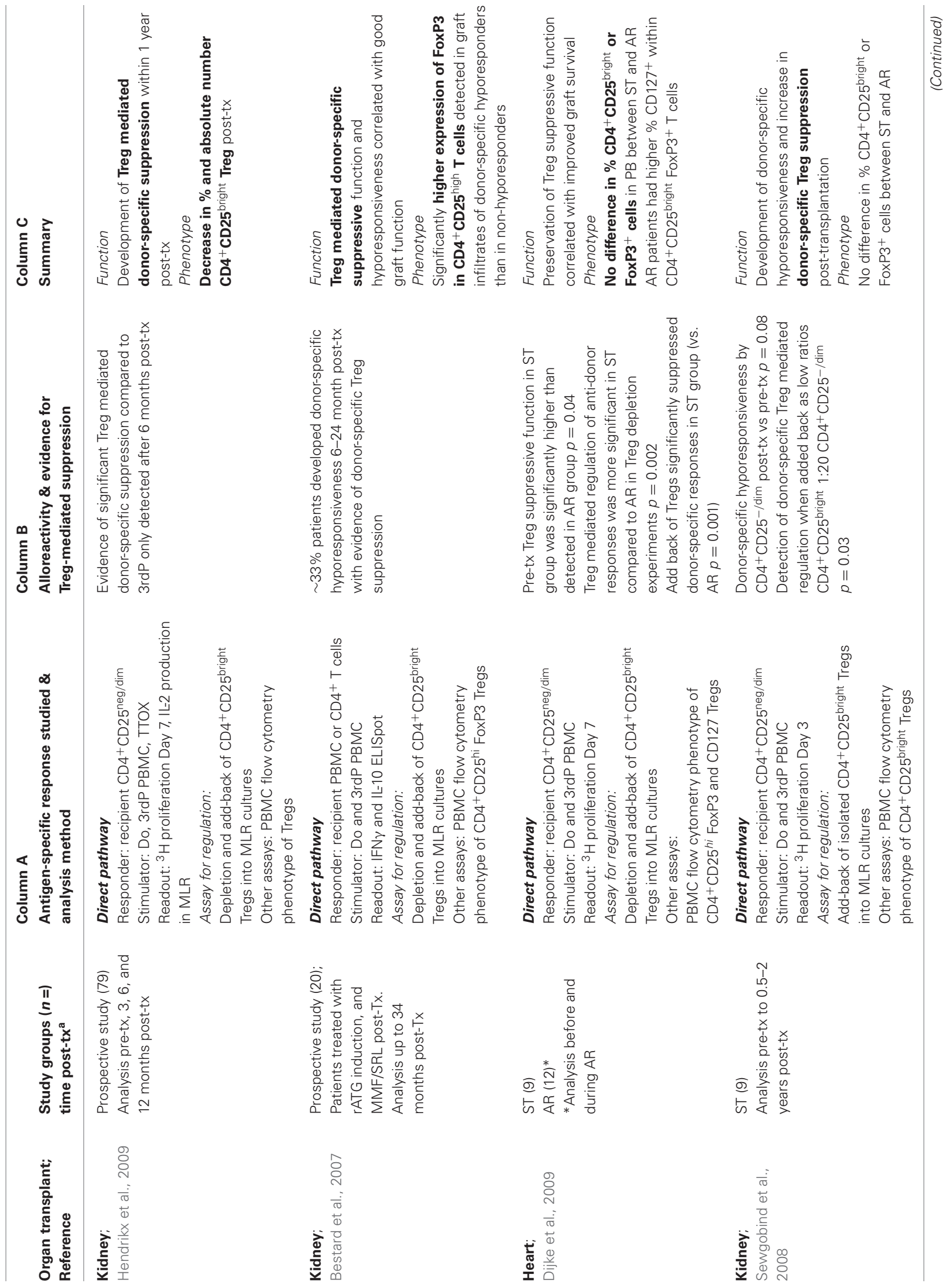




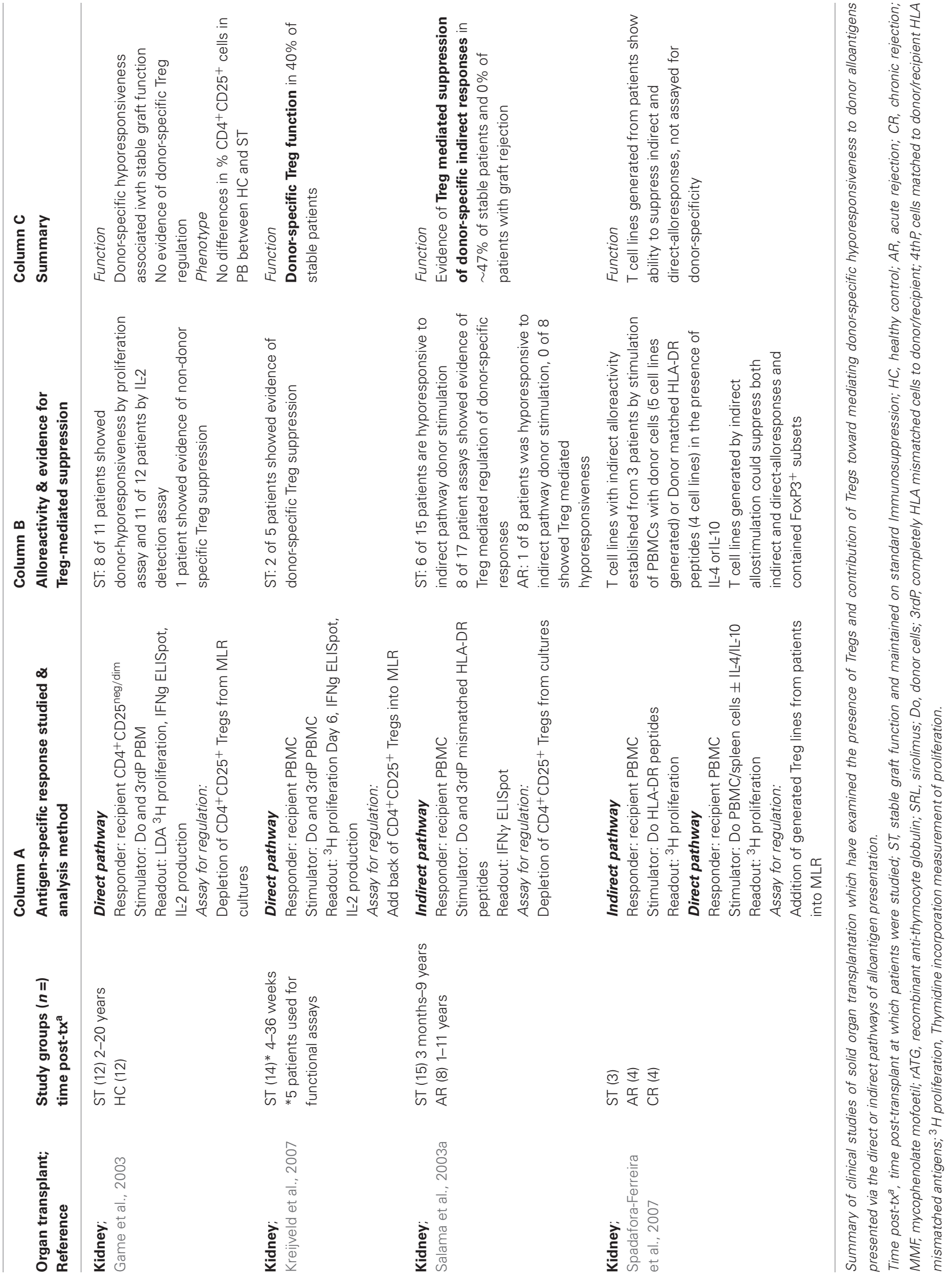




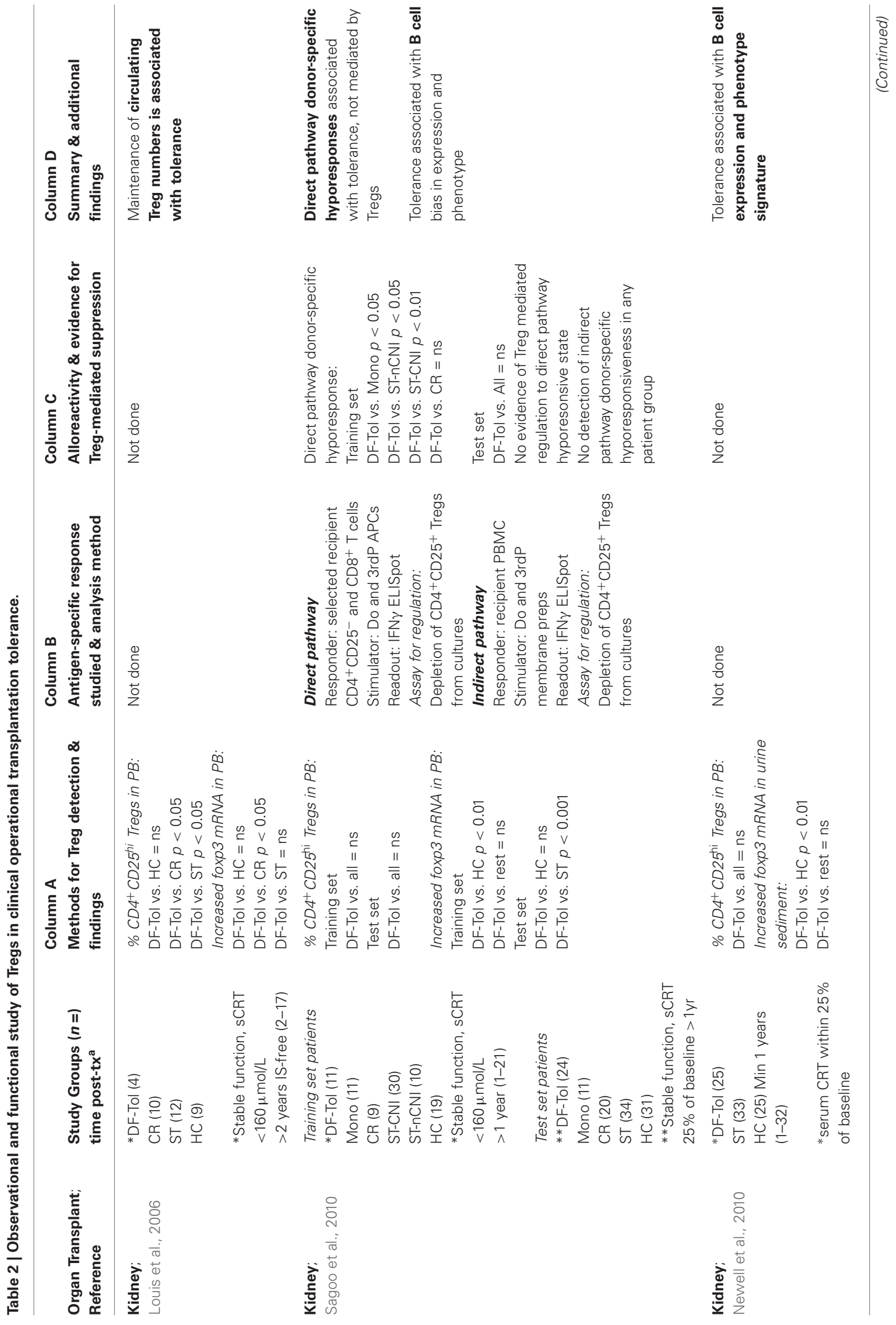



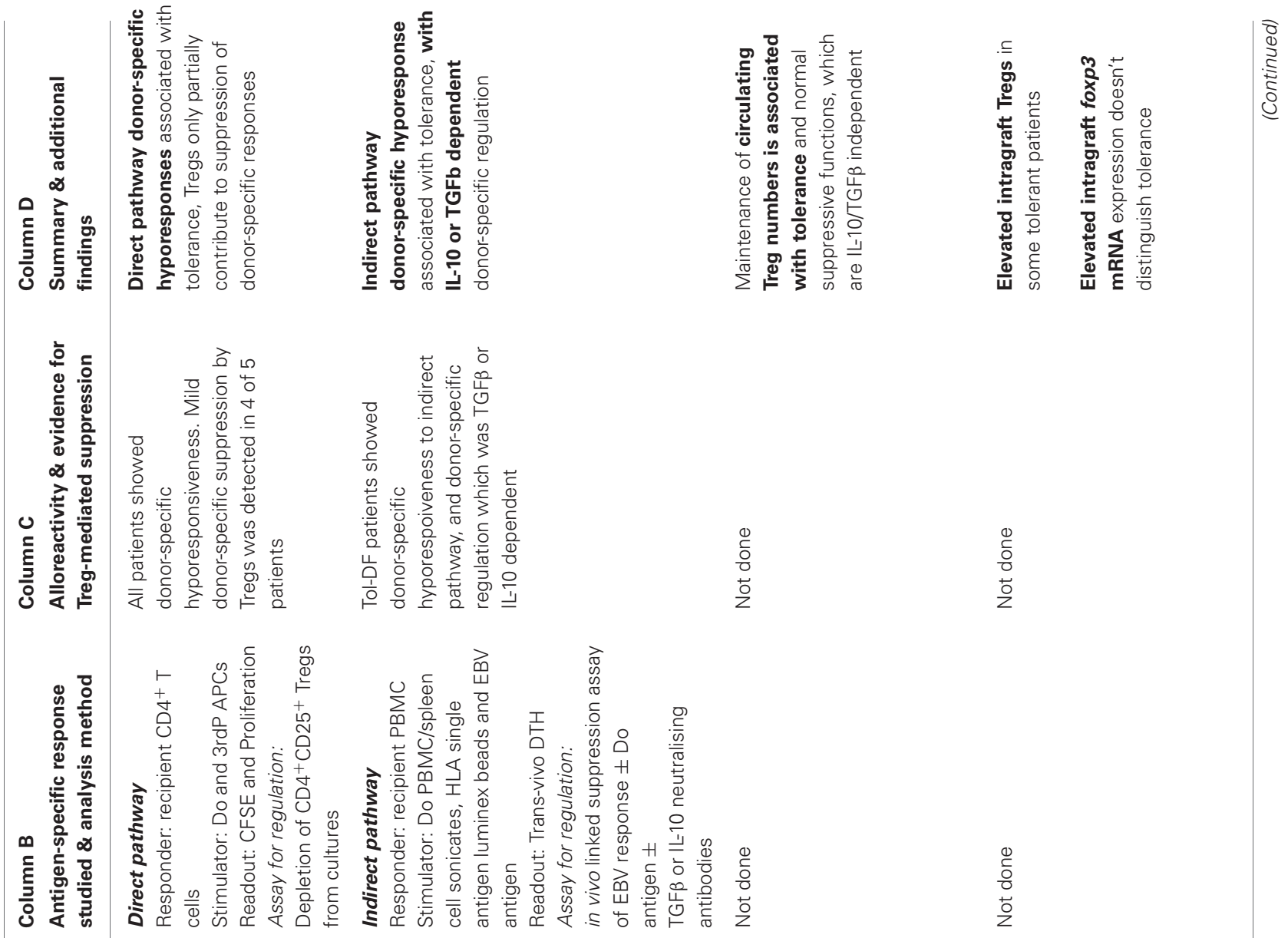

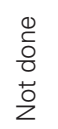

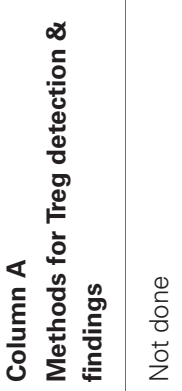

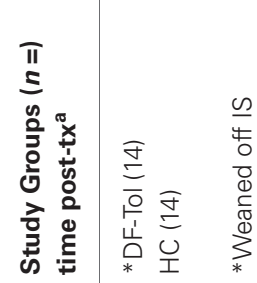

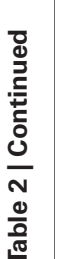

0
$\stackrel{0}{0}$
$\frac{0}{0}$
0
0

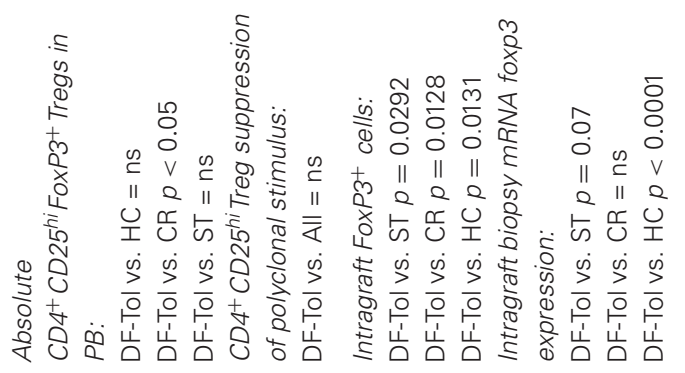

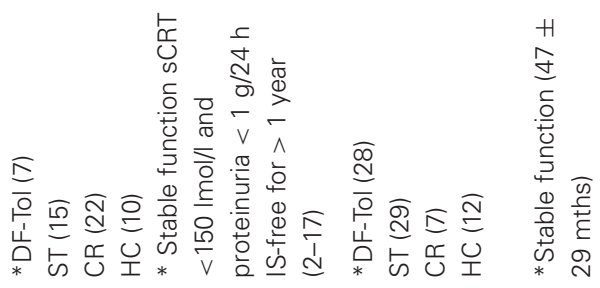

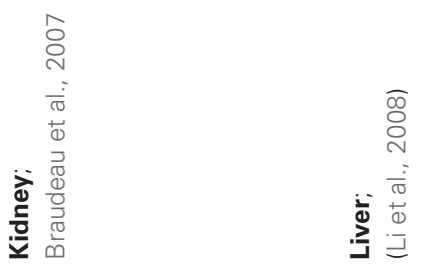




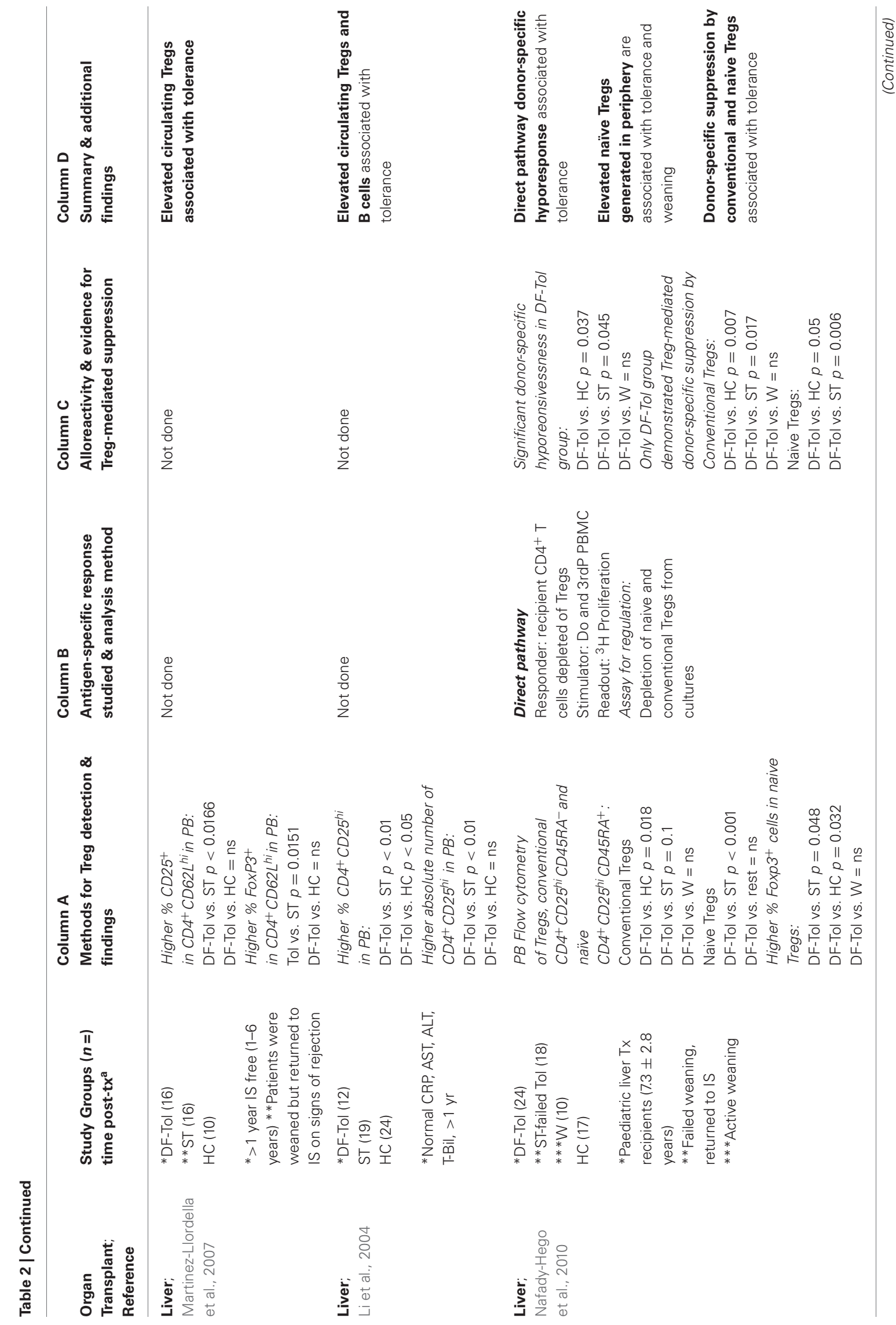




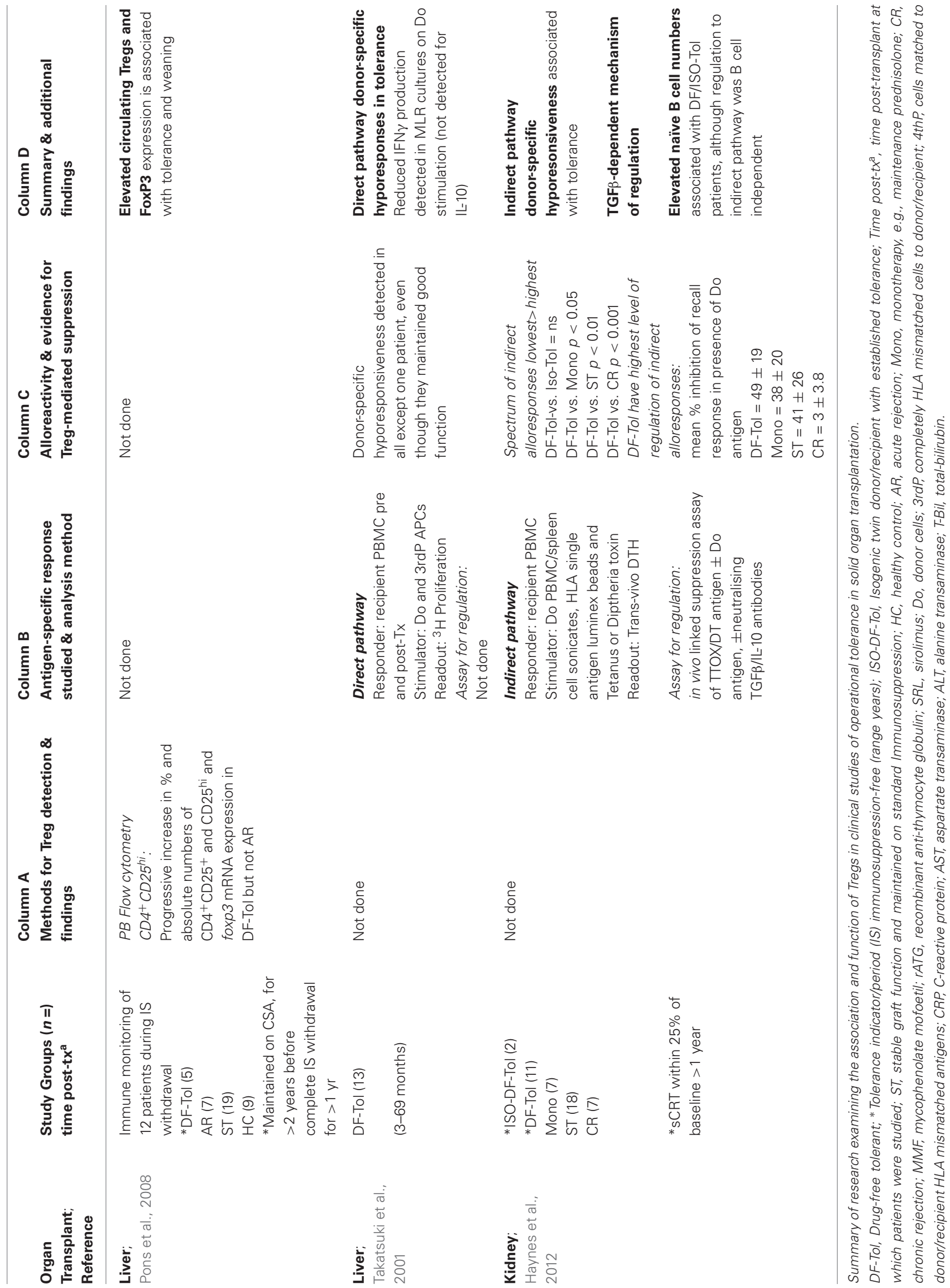




\section{EVIDENCE FOR DONOR-SPECIFIC TREG-MEDIATED REGULATION OF ALLOIMMUNITY}

Measuring recipient alloreactivity toward donor antigen presented by the direct or indirect pathways has been achieved using several ex vivo methods as summarized in Tables 1 (Column A) and 2 (Column B), and has evidenced that detectable active donor-reactive immunity is in general correlated with poor graft outcome and development of acute and chronic graft rejection, respectively (Table 1 Column B and Table 2 Column C; Vella et al., 1997; Ciubotariu et al., 1998; Poggio et al., 2004; Hernandez-Fuentes and Lechler, 2005). Furthermore, by comparing recipient $\mathrm{T}$ cell responder frequencies against donor stimulation to that of HLA mismatched third party (3rdParty) stimulation, it can be used as a method to detect donorspecific hyporesponsiveness and, therefore, determine whether established stable graft function or immunological tolerance is alloantigen-specific. Monitoring of donor-reactive immune responses has demonstrated that hyporesponsiveness to the direct pathway can develop shortly after solid organ transplantation and is in general associated with stable graft function (Hornick et al., 1998; De Haan et al., 2000). Donor-specific cytotoxic or T cell hyporesponsiveness has been detected in kidney (Ghobrial et al., 1994; Mason et al., 1996; Mestre et al., 1996; Hornick et al., 1998; Baker et al., 2001b), heart (Hu et al., 1994; Hornick et al., 2000; Van Hoffen et al., 2000) and lung (De Haan et al., 2000) transplantation, although this is not a universal finding (Eberspacher et al., 1994; Loonen et al., 1994; Steinmann et al., 1994; Oei et al., 2000). In addition, hyporesponsivessness to donor antigen presented by the indirect pathway has also been described (Salama et al., 2003b). As shown in Tables 1 and 2, the contribution of Tregs toward regulation of donor alloreactivity can be measured by the recovery of effector functions or proliferation when Tregs are removed or added into an assay in which donor alloantigen is used as a stimulator of either the direct or indirect $\mathrm{T}$ cell alloresponse. Again, comparison of suppressive activity toward a 3rdParty stimulator can further reveal whether Tregs have alloantigen-specific suppressive functions.

Our review of clinical studies which have examined the contribution of Tregs toward established donor-hyporesponsiveness shows a high degree of concordance in demonstrating donorspecific Treg mediated suppression of T cell alloreactivity toward direct (Velthuis et al., 2006, 2007; Bestard et al., 2007; Kreijveld et al., 2007; Akl et al., 2008; Sewgobind et al., 2008; Hendrikx et al., 2009) and indirect (Salama et al., 2003b; Spadafora-Ferreira et al., 2007) pathway anti-donor responses in patients with stable allograft function. Two of these studies were prospective and were, therefore, able to show that donor-specific Treg activity with direct pathway specificity developed relatively early on post transplantation from 6 months onwards (Bestard et al., 2007; Hendrikx et al., 2009). Within the studies examined the percentage of stable allograft recipients with detectable evidence of donor-specific Treg functions ranged from 20 to $83 \%$ of donorhyporesponsive patients between study cohorts. Some studies however, were either unable to detect any donor-specific $\mathrm{T}$ cell hyporesponsiveness (Baan et al., 2007), or unable to uncover any donor-specific Treg activity despite patients showing donorspecific T cell hyporesponses to direct pathway donor stimulation
(Game et al., 2003). These variations may be in part explained by the differing immunocompetence and immune status between individual patients and within patient cohorts based on their pre- and post-transplant immunosuppressive regimens, or simply technical peculiarities of the assays performed. Incongruence's may also be influenced by differences in time post-transplantation that patients were screened for donor-specific Treg activity, where in addition to Tregs, other more dominant donor-specific immunoregulatory mechanisms may be actively contributing toward the detected dampening of anti-donor responses.

In support of this latter hypothesis, a study examining regulation of direct pathway alloreactivity in tolerant liver transplant recipients (Yoshizawa et al., 2005), suggests that donor alloantigen specific Treg activity is one of multiple mechanisms that may contribute to the maintenance of liver graft survival. Yoshizawa et al. were able to detect an increase in donor-directed alloreactivity after depletion of Tregs from in vitro MLR assays, however tolerant recipient $\mathrm{T}$ cells still remained largely hyporesponsive to donor stimulation suggesting other mechanisms such as clonal deletion, induction of donor-specific cell anergy or involvement of other immunomodulatory cell subsets were established during tolerance. Further evidence for this is provided by work from our group as part of the Indices of Tolerance and Riset consortium, where we were able to correlate direct pathway donor-specific hyporesponsiveness with tolerance in renal transplant patients, but this could not be attributed to $\mathrm{CD} 4{ }^{+} \mathrm{CD} 25^{+}$Treg mediated donor-specific functions by ex vivo analysis (Sagoo et al., 2010). As increased numbers of Tregs were more strongly associated with operational tolerance in liver transplantation as described earlier, the findings by Nafady-Hego et al. may be readily anticipated (Nafady-Hego et al., 2010). In their ex vivo functional assays to study donor-specific Treg suppression, Nafady et al. found that only the patient cohort with established tolerance demonstrated donor-specific Treg mediated regulation of donordirected $\mathrm{T}$ cell alloresponses, with patients undergoing active weaning showing a similar emerging although not significant effect.

Drawing any firm conclusions from these findings is a challenge as very few studies to date have directly assessed Treg activity in clinical transplantation tolerance. However, the data reviewed in Tables 1 (Columns B and C) and 2 (Columns C and D) clearly indicate that donor-specific hyporesonsivess to the direct and indirect pathways of alloantigen presentation are features of stable graft function and also operational tolerance. Furthermore they suggest that naturally occurring Tregs may play a prominent role in the establishment and possibly maintenance of donor-specific immunological tolerance in liver transplantation. This is an important aspect which can only be assessed by clinical studies which perform longitudinal immune monitoring of transplant recipients during immunosuppression weaning protocols as is more routinely performed in liver transplantation. In contrast, while in kidney transplantation Tregs with direct pathway donor-specificity appear to contribute toward suppression of donor-specific responses during stable graft function or the phase of tolerance induction, they do not appear to play a prominent role in toward the maintenance of established operational tolerance. 
Although there is evidence of Treg-mediated regulation of indirect pathway directed anti-donor responses in stable renal transplant patients (Salama et al., 2003a), clinical studies of operational tolerance suggest that maintenance of the immunological donor-specific hyporesponsive state can also be attributed to other immuoregulatory processes than naturally occurring Tregs. Several years ago, VanBuskirk et al. were able to demonstrate that some patients displaying stable tolerance to either a kidney or liver allograft had evidence of donor-specific regulation of indirect pathway $\mathrm{T}$ cell responses. This was detected using a trans-vivo delayed-type hypersensitivity (DTH) linked suppression assay, measuring DTH swelling responses to tetanus toxin recall antigen stimulation when applied with or without donor antigen (VanBuskirk et al., 2000). This study identified regulation of donor-specific responses was dependent on either IL-10 or TGF $\beta$, although no further analysis of the mechanistic basis or source of either cytokine was studied. Following on from this work, Haynes et al., have recently been able to correlate both reduced $\mathrm{T}$ cell responses to indirectly presented donor alloantigens and evidence of active regulation of indirect alloreactivity with improved kidney transplant outcome (Haynes et al., 2012). Again using the trans-vivo DTH assay, they were able to show that tolerant patients had reduced donor-specific $\mathrm{T}$ cells responses with reactivity toward indirectly presented donor antigens, which were actively regulated through a TGF- $\beta$ dependent mechanism detected using an in vivo linked suppression assay. Although again, immune regulation was not directly attributed to antigen-specific naturally occurring FoxP3 ${ }^{+}$Tregs or any particular lymphocyte subset, this certainly implies a role for adaptive or induced Th3 Treg mediated regulation, by CD4 or possibly CD8 T cell subsets. In this study, the importance of alloimmune priming and immune regulation of the indirect pathway for tolerance induction was also very clearly illustrated by the complete absence of indirect pathway alloresponses detected in identical twins receiving isogenic kidney transplants. Haynes et al. also performed a parallel assessment of other kidney graft patients including those with stable graft function and those undergoing chronic rejection, and showed a progressive spectrum of immune responses to the indirect pathway and the degree of active regulation of this alloresponse, associated with graft function, where patients with biopsy proven chronic rejection had the highest level of indirect alloreactivity, with the lowest regulatory ability.

These studies highlight the significance of active processes of regulation of the indirect pathway of alloantigen presentation in tolerance, suggesting that deletion may not be the primary mechanism involved, however they did not examine and, therefore, exclude the role of naturally occurring $\mathrm{CD} 4{ }^{+} \mathrm{CD} 25^{\text {high }} \mathrm{FoxP} 3^{+}$ Tregs, either their direct suppressive activities or their ability to mediate linked suppression and thereby induce alternative networks of immunomodulatory cells. Indeed, the clinical studies of operational tolerance reviewed here are all restricted by their assessment of only limited immunoregulatory cellular phenotypes or mechanisms. Nonetheless, what can be inferred from these studies is that in both liver and kidney transplantation tolerance, naturally occurring Tregs with donor-specificity may be related to immune regulation of the alloresponses early posttransplantation, to induce transplantation tolerance. There then appears to be some divergence between allografted tissues which requires further investigation, however current data suggests that in operational kidney transplantation tolerance, immunoregulation mediated by Tregs does not remain a dominant mechanism. An emerging hypothesis is, therefore, that Tregs with indirect allospecificity may induce other immunosuppressive mechanisms through linked or bystander suppression to generate infectious tolerance which are involved in maintenance of the tolerant state. We can find evidence to support this hypothesis by examining the mechanisms and immunological factors identified following experimental and clinical transplantation tolerance induction protocols.

\section{LESSONS ON RELEVANCE OF DONOR-SPECIFIC TREGS FROM TOLERANCE INDUCTION PROTOCOLS}

Linked suppression is a feature of immune regulation which can be elicited by Tregs with indirect allospecificity, whereby a Treg can encounter an APC presenting its specific MHC:peptide complex and can exert suppression upon other T cell responses, with specificity for other unrelated antigens also presented by the same APC, namely via the indirect pathway (Chen et al., 1996; Wise et al., 1998; Niimi et al., 2001). Mechanistically, linked suppression is achieved through many of the classical suppressive functions of Tregs described, such as modulation of APC functions to generate tolerogenic functions, Treg-T cell competition for space or ligands on the APC both of which can result in anergy, or local production of immunosuppressive cytokines or factors which modulate lymphocyte functions (Qin et al., 1993; Waldmann et al., 2006). In addition to induction of adaptive $\mathrm{CD}^{+}{ }^{+} \mathrm{CD} 25^{+} \mathrm{FoxP}^{+}$Tregs, these mechanisms may result in the generation of other immunomodulatory cell subsets, such as the recently described $\mathrm{CD}^{+}{ }^{+} \mathrm{CD} 28^{-}$suppressor T cells (Suciu-Foca et al., 2003), Tr1 cells (Battaglia et al., 2006), or Th3 cells, the importance of which has been further underlined in transplantation tolerance by recent work from the Burlingham research group described earlier (VanBuskirk et al., 2000; Haynes et al., 2012). The presence of donor-specific Tregs may, therefore, act to dampen the inflammatory alloimmune response early on posttransplantation by suppressing alloimmune $\mathrm{T}$ effector responses for induction of transplantation tolerance. Once a tolerogenic environment is established in vivo, subsequent antigen presentation may occur predominantly via the indirect pathway within a tolerogenic environment, and depending on the degree of HLA mismatching, resulting in the expansion of naturally occurring Tregs, or the induction of adaptive or induced Treg populations, such as the Th3 to propagate infectious tolerance and maintain an operational tolerant state. This may explain the incongruence between clinical studies that have examined the presence and activities of Tregs with direct pathway allospecificity during the late transplantation period. Although it remains to be formally demonstrated in a clinical setting, several studies have implicated a direct link between Tregs and induction of other immunoregulatory processes, which is emphasized by the persistence of the indirect pathway and indirect allospecific Treg functions.

Review of experimental tolerance induction strategies have shown that in addition to clonal deletion, anergy and exhaustion, immune regulation mediated by Tregs form a common 
mechanistic basis in achieving indefinite graft survival, particularly using methods such as DST, tolerogenic DCs and also costimulatory blockade (Sykes, 2007). Many tolerance induction protocols have been shown to require active presentation of alloantigen through the indirect pathway (Yamada et al., 2001; Niederkorn and Mayhew, 2002; Rulifson et al., 2002). This corresponds to studies of allograft tolerance in mice, where Tregs have been described as being generated by indirect presentation, which can then exert their suppressive properties against donor alloantigen presented by the indirect pathway (Wise et al., 1998; Hara et al., 2001). Also as mentioned previously, the detection of effective immune regulation of donor alloreactivity to the indirect pathway in clinical studies is correlated with stable graft function and tolerance. As several studies have indicated that thymically derived naturally occurring $\mathrm{CD} 4{ }^{+} \mathrm{CD} 25^{+}$Tregs have a higher propensity for recognition of self-MHC and thus indirect allospecificity (Jordan et al., 2001; Apostolou et al., 2002; Romagnoli et al., 2002; Hsieh et al., 2004), it is, therefore, conceivable that presentation of alloantigen by the indirect pathway following transplantation results in the preferential activation and expansion of Tregs with indirect allospecificity. This may in part explain their improved efficacy in experimental models of indirect pathway antigen presentation compared to direct pathway antigen presentation (Sanchez-Fueyo et al., 2007), and support their role in the early induction phase of transplantation tolerance.

The requirement of the indirect pathway and the role of Tregs in tolerance induction are heavily implicated by tolerance induction protocols using DST or hematopoietic stem cell transplantation (HSCT) in experimental and clinical transplantation (Kishimoto et al., 2004). Generation of mixed chimerism as an approach to achieve tolerance to a solid organ transplant aims to generate both peripheral and central tolerance to the allograft, and has recently been extensively reviewed by Pasquet et al. (2011). Establishing mixed chimerism creates an in vivo situation where alloantigen presentation via the indirect pathway is significantly potentiated in activity and intensity and may, therefore, be more permissive to the promotion of indirect allospecific Tregs and tolerance induction. Le Guern et al. have provided experimental data which links the mixed chimerism approach for tolerance induction, with Treg induction and linked suppression. In a murine model of fully mismatched heart transplantation $(\mathrm{C} 57 \mathrm{BL} / 6 \rightarrow \mathrm{CBA})$, recipient mice received an autologous BMT $\left(\mathrm{I}-\mathrm{A}^{\mathrm{k}+}\right.$ ) which had been retrovirally transduced to express a single donor MHC Class II donor allele (I-A $\mathrm{A}^{\mathrm{b}}$ ), followed by a donor or 3rdParty heart allograft. This protocol resulted in the induction of donor-specific tolerance, in the complete absence of sustained immunosuppression, which was associated with immune deviation from a Th1 to Th2 predominate cytokine response and with no indications of chronic rejection associated vasculopathy (LeGuern, 2004; LeGuern et al., 2010). Furthermore, they were able to transfer protection against graft rejection to naïve recipients through $\mathrm{CD}^{+}{ }^{+} \mathrm{CD} 25^{+}$FoxP3 ${ }^{+}$Tregs isolated from tolerant mice.

An impressive Phase II clinical study by Leventhal et al. (2012) has employed the mixed chimerism approach to show induction of stable operational tolerance in all their study patients that underwent HLA-mismatched combined HSCT and kidney transplantation. This study used a protocol which included transfer of pre-plasmacytoid tolerogenic DC graft facilitating cells in addition to HSC donor inoculum, which by in vitro and in experimental in vivo research had previously been shown to mediate induction of $\mathrm{CD} 4{ }^{+} \mathrm{CD} 25^{+}$FoxP $3{ }^{+}$donor-specific Tregs. In patients whom developed durable chimerism, an increase in the ratio of Tregs to $\mathrm{T}$ effectors was detected, along with lack of donor alloreactivity toward the recipient, which may explain the absence of GvHD within the cohort. An additional observation, which we discuss later, was the expansion of $\mathrm{CD} 19^{+}$ $B$ cells by a large proportion of the patients, occurring within the first year post-transplantation. Based on detectable responses to 3rd Party alloantigens in vitro, it is likely that established donor-specific immune modulation in these patients was mechanistically linked to the induction of donor-specific Tregs. In another study of combined BMT and kidney transplantation in HLA-mismatched individuals, Tregs were found to play a more dominant role early post-transplantation, being expanded in numbers in the periphery and demonstrating the development of donor-specific suppressive activity compared to pre-transplant function. However at 6-12 months post-transplantation, only some study patients displayed evidence of donor-specific suppression by Tregs, which was no longer detectable after 1 year, despite the maintenance of donor-specific hyporesponsiveness. This suggests other forms of immune regulation such as antigen-specific $\mathrm{T}$ effector cell depletion or anergy may have evolved to maintain allograft tolerance (Andreola et al., 2011). These studies suggest that maintenance of established tolerance may be manifested through $\mathrm{CD}^{+}{ }^{+} \mathrm{CD} 25^{+} \mathrm{FoxP}^{+}$Treg dependent or independent activity, which may act in concert with or independent of several other induced immunomodulatory mechanisms.

The use of donor-specific Tregs for transplantation immunotherapy, therefore, provides an opportunity for the generation of infectious tolerance and as such, an improved likelihood of developing stable long-term donor-specific unresponsiveness (Cobbold and Waldmann, 1998; Waldmann et al., 2006). We next explore the concept of linked suppression in the context of the improved capacity of donor-specific Tregs to mediate maintenance of tolerance induction.

\section{DONOR-SPECIFIC TREGS AND CONSEQUENCES OF REGULATION THROUGH LINKED SUPPRESSION}

As described, a key advantage of immunotherapy using Tregs with indirect donor allospecificity is that they have the capacity to mediate linked suppression. This allows them to exert control over broader effector arms of the alloimmune response, which is particularly relevant for the control of alloantigen-specific B cells of the alloimmune response.

One of the main effector mechanisms of alloreactive $\mathrm{T}$ cells with indirect allospecificity is through the provision of T cell help to B cells, which results in the generation of the humoral alloantibody response to an allograft (Suciu-Foca et al., 1995; Colvin, 2007), and leads to alloantibody mediated chronic graft rejection. The dominant role of $\mathrm{T}$ cells with indirect pathway allospecificity in providing germinal center help to B cells for alloantibody induction and graft rejection has recently been firmly established. By adoptive transfer of $\mathrm{CD} 4^{+} \mathrm{T}$ cells with indirect allospecificity (BALB/c Class I H2- $\mathrm{K}^{\mathrm{d}}$ molecule presented in the context 
of C57BL/6 class II I-A $\mathrm{A}^{\mathrm{b}}$ ) or $\mathrm{T}$ cells with direct allospecificity $\left(\mathrm{CD} 4^{+} \mathrm{T}\right.$ cells with direct specificity for $\left.\mathrm{I}-\mathrm{A}^{\mathrm{bm} 12}\right)$, Conlon et al., were able demonstrate that only $\mathrm{T}$ cells with indirect allospecificity had the capacity to provide B cell help and induce an alloantibody response to a heart allograft (BALB/c $\rightarrow$ C57BL/6), whereas $\mathrm{T}$ cells with direct allospecificity alone were incapable (BALB/cxBM12 $\rightarrow$ C57BL/6; Taylor et al., 2007; Conlon et al., 2012). Interactions between cognate $T$ cells and $B$ cells, recognizing different allogeneic peptides presented by the same APC also promotes epitope spreading of the $\mathrm{T}$ cell and alloantibody responses, resulting in the recognition and alloimmune targeting of effector responses to more cryptic antigenic determinates over the lifetime of the transplant. This correlates with the main pathological markers of chronic rejection which are typically that of wound healing such as fibrosis or vasculitis, where proinflammatory cytokines generated by antibody-mediated complement or cellular dependent mechanisms of allograft damage, induce endothelial and epithelial hyperproliferation. Indeed in clinical transplantation, epitope spreading has been detected in patients with detectable indirect pathway $\mathrm{T}$ cell alloreactivity with evidence of chronic allograft dysfunction (Vella et al., 1997; Ciubotariu et al., 1998; Suciu-Foca et al., 1998; Hornick et al., 2000). Previous work from our laboratory has demonstrated the unique capacity of Tregs with indirect allospecificity to control alloantibody mediated vasculopathy in experimental heart and skin graft models (Tsang et al., 2009). Using both MHC-mismatched and semi-allogeneic transplantation models, Tregs generated with both direct- and indirect pathway allospecificities were found to be more effective at inducing indefinite survival of heart transplants than Treg cell lines generated for direct allospecificity alone. Whilst Tregs with allospecificity for the direct pathway were only marginally less effective at inducing indefinite graft survival compared to Tregs with both direct and indirect pathway allospecificities, Tregs with indirect allospecificity were essential to prevent chronic vasculopathy, determined by allograft histopathology. These findings correspond to clinical observations, where Tregs with indirect pathway donor-specific suppressive activity in stable renal transplant recipients have been shown to be able to regulate a shift in recipient alloreactivity to different donor MHC epitopes during the post-transplant period (Salama et al., 2003b).

These data clearly argue that development of Tregs with donorspecificity for the indirect pathway as a cell therapy product for transplant recipients is likely to be critical for the induction of long-term graft survival, enabling immunoregulatory mechanisms to adapt to the evolving immune response through the ability of Tregs to control epitope spreading through linkedsuppression. Recipient B cell presentation of donor graft alloantigens is now known to make a critical contribution toward graft rejection (Noorchashm et al., 2006). As only Tregs with indirect specificity would have the capability of interacting directly with its cognate MHC: donor allopeptide complex as presented by a B cell, it would, therefore, have the potential to modulate the B cell alloresponse. Treg-mediated modulation of B cell activity has been evidenced in a previous study of MHC class I mismatched heart allograft rejection mediated by the indirect pathway, where graft rejection, induced specifically via $\mathrm{CD} 4^{+} \mathrm{T}$ cell dependent induction of alloantibody, was prevented using a tolerance induction protocol of anti-CD4 and DST, which was shown to generate Tregs with indirect allospecificity with the capacity to suppress alloantibody generation (Callaghan et al., 2007).

In addition to the indirect regulatory $\mathrm{T}$ cell effect on $\mathrm{B}$ cell activity, through inhibition of helper $\mathrm{T}$ cell activity, Tregs have also been shown to modulate B cell activity through a number of direct suppressive mechanisms. For example, antigenspecific murine Tregs raised against a common allergen, through in vivo administration of an immunodominant peptide, have been shown to mediate $B$ cell killing on recognition of specific epitope:MHC complexes through Treg cytolytic activity of FasFas-L interactions (Janssens et al., 2003). Lim et al. (2004) have shown that on antigen-mediated activation, Tregs can modulate their expression of germinal center (GC) B cell follicular zone homing chemokine receptors (increase CXCR5, decrease CCR7) and migrate to the $\mathrm{T}$ cell $\mathrm{B}$ cell boundary areas within human lymphoid tissue, where they can then directly prevent $B$ cell class switching and Ig production (Lim et al., 2005). This latter study went further and by isolating Tregs and B cells from human lymphoid tissue, were able to demonstrate that Tregs were not only able to directly suppress B cell class switching, detected by monitoring Ig transcript analysis in ex vivo transwell assays, but were also able to suppress the helper $\mathrm{T}$ cell response, by preventing CXCL13 secretion. More recent studies in mouse have shown that naturally occurring Tregs can migrate and reside in the GC follicular zone where they regulate $\mathrm{B}$ cell humoral responses, and that inhibiting their migration to these zones (using B cells derived from CXCR5 ${ }^{-1-}$ mice) results in aberrant B cell IgM, IgA, IgG1, and IgG2b antibody production (Wollenberg et al., 2011). More recently experimental evidence suggests that Tregs may also have the capacity to protect pre-sensitized individuals, through their ability to control plasma B cell activity (Jang et al., 2011). Tregs are, therefore, key in preventing B cell mediated graft destruction and limiting indirect alloimmunity, which correlates with an absence of donor-specific alloantibody in clinical transplantation tolerance and experimental models of transplantation tolerance.

Although the classic view of B cells in transplantation has focused on their pathogenic activities, an alternative emerging view is that of the complimentary roles of Regulatory B cells (Bregs) and Tregs. Bregs have recently been identified to play roles in regulating autoimmunity in experimental models of collageninduced arthritis, experimental autoimmune encephalitis (EAE) and colitis, which is associated with B cell production of IL-10 (BR1 or B10 cells in human or mouse respectively) or TGF $\beta$ production (Mauri and Blair, 2010). Ashour and Niederkorn have demonstrated that Breg and Treg collaboration are associated with the process of immune modulation in anterior chamber associated immune deviation (ACAID). Their study showed that following antigen transfer into the anterior chamber of the eye, the APC function of B cells was essential in generating peripheral tolerance through the induction of $\mathrm{CD}_{4}^{+}$and $\mathrm{CD} 8^{+}$regulatory $\mathrm{T}$ cells (Ashour and Niederkorn, 2006). Further evidence is provided in a model of EAE, where depletion of B cells was related to a lack of recovery from the disease and delayed emergence of FoxP3 ${ }^{+}$cells within the CNS (Ray et al., 2012). Interestingly, in this model, B cell induction of Treg proliferation was found be 
dependent on B cell expression of glucocorticoid-induced TNF ligand (GITRL) rather than IL-10 expression. In fact, B cells are now becoming well described in their abilities to both positively and negatively regulate $\mathrm{T}$ effector responses, in addition to both induce and expand Tregs (Lund and Randall, 2010). Thus, an emerging controversial role of B cells in immunity is apparent, which is particularly surprising given the established contribution of allospecific B cells and alloantibody toward organ allograft rejection.

Currently very few studies have identified a role for Bregs in the context of transplantation tolerance (Le Texier et al., 2011; Wang et al., 2011). Le Texier et al. have recently revealed that B cells isolated from tolerant recipients in a rat model of heart transplantation can mediate infectious tolerance on adoptive cell transfer (Le Texier et al., 2011). In this model, B cells infiltrated and were localized to the tolerated organ, did not undergo class switching being maintained as $\operatorname{IgM}^{+}$cells within the tissue and the periphery, and were found to express high levels of BANK-1 and the inhibitory FcgR2b receptor, indicating the generation of an inhibitory B cell phenotype. In clinical transplantation, the study by Haynes et al. mentioned earlier has been the first to examine the functional regulatory contribution of Bregs. In their study, they observed highest regulation of indirect pathway alloreactivity in operationally tolerant recipients which was predominantly TGF $\beta$ dependent. One of the methods they used to examine a Breg effect was by incorporating B cell depletion into their studies measuring the in vivo DTH response, which showed regulation of indirect alloreactivity was mediated through a B cell-independent mechanism. These two studies suggest that maintenance of established tolerance may be more dependent on B cells, rather than tolerance induction. One possibility may be that following immunosuppression withdrawal, Breg populations may emerge which are actively involved in mediating tolerance through other mechanisms such as IL-10 production (Iwata et al., 2011), which allows speculation that they then have the potential to promote other immunomodulatory mechanisms such as induction of $\operatorname{Tr} 1$ Tregs. These studies correspond with the B cell dominant gene expression profile and peripheral expansion of B cells detected within operationally tolerant patient cohorts (Newell et al., 2010; Pallier et al., 2010; Sagoo et al., 2010), some of which show alterations in specific memory or transitional B cell subsets. One of the main difficulties in assessing the role of Bregs in clinical transplantation tolerance is the current lack of a definitive Breg marker. In view of these findings, a resurgent interest in the regulatory and allopriming role of $\mathrm{B}$ cells in transplantation tolerance is occurring (Adams and Newell, 2012) which may identify a Breg subset phenotype. More research may also reveal whether Tregs can influence or alter the generation of a Breg or B cell repertoire composed of more tolerogenic anti-inflammatory subtypes post-transplantation. This and other questions raised throughout this review may only be answered by the sequential immunological monitoring of patients pre- and post-transplantation, operationally tolerant patients or patients undergoing tapered weaning protocols, as are currently being performed within the GAMBIT study (Genetic Analysis and Monitoring of Biomarkers of Immunological Tolerance) at King's College London UK.

\section{SUMMARY AND PERSPECTIVE}

Achieving transplantation tolerance may be viewed as two interlinked phases, tolerance induction and maintenance of established tolerance. This review finds that while Tregs are associated with, and in some studies, integral to tolerance induction, Tregmediated immune regulation may not be a consistent feature of long-term tolerance, although this may be an organ-specific phenomenon. To obtain a clearer perspective of the role of Tregs in the process of establishing tolerance, the evolving alloimmune response needs to be studied on a longitudinal basis in terms of several immunomodulatory population phenotypes, e.g., Treg, Tr1, Th3, Bregs, and functions, using an array of complementary methods, with parallel monitoring of clinical allograft function. This sort of comprehensive immune monitoring will require a solidly collaborative approach, but may reveal the true potential of Tregs for induction of transplant tolerance.

In developing an optimized Treg therapy for clinical induction of transplantation tolerance, Tregs with indirect donoralloantigen specificity are likely to be most effective at delivering long-term stable graft survival, which is attributed to their ability to suppress multiple immune cell types, and their potential to interact with and promote other immunoregulatory processes, through linked suppression and infectious tolerance. New findings highlight an emerging role of the semi-direct pathway in alloantigen presentation, which combined with the prominent role of the indirect pathway in driving rejection and tolerance, makes a stronger case for the use of indirect allospecific Treg therapy. Indeed, although Tregs with direct allospecificity may be able to deliver localized immune regulation to the allograft, they would be limited in their ability to control the effector and allopriming arms of the indirect alloresponse, which occur at different anatomical sites, however this would again be dependent upon the degree of HLA matching between the donor and recipient. Furthermore, although direct allorecognition can lead to a vigorous inflammatory response resulting in direct cell mediated damage and hyperacute rejection of allografted tissues, it can be effectively controlled with immunosuppressive drugs to avoid acute rejection, as evidenced by the high success rate of graft acceptance early post-transplantation.

Clinical translation of Treg cell therapy faces several major challenges. First and foremost is the challenge of developing clinically transferrable protocols for the selection and expansion of human donor alloantigen-specific Tregs, particularly Tregs with indirect allospecificity (Jiang et al., 2006; Peters et al., 2008). Very little progress has been made in this respect, which is primarily due to the complexity of studying indirect allorecognition with the tools and methods currently available, which is further complicated by the breadth of mismatched allogeneic HLA peptides that alloreactive $\mathrm{T}$ cells may respond to (Waanders et al., 2008). The advantage is that by generating Tregs with specificity for a single immunodominant allopeptide, the Tregs will be able to mediate regulation against all allogeneic peptides through linked suppression as evidenced by the work described above (LeGuern et al., 2010). Indeed, work is currently underway in our laboratory to generate human Tregs with indirect allospecificity, to demonstrate this potential in an in vivo humanized mouse xenograft model. 
A potentially serious caveat to using donor alloantigen-specific Tregs in vivo is the potential of transferring contaminating alloreactive $\mathrm{T}$ effectors, or indeed alloantigen-specific Tregs with the capacity to convert to proinflammatory Th17 effector cells, particularly in light of their emerging role in contributing toward graft rejection (Burlingham et al., 2007; Chadha et al., 2011). Efforts to limit this possibility are focusing on identifying key triggers and Treg subset markers which describe Tregs with Th17conversion potential. However, do we really need to limit transfer of effector populations of Th17 differentiating cells or will the transfusion of Tregs into a regulatory or suppressive environment induced by immunosuppression for example, result in immunodominance by Tregs? Treg cell products currently being used in clinical HSCT can often be composed of only $50 \%$ FoxP3 ${ }^{+} \mathrm{CD}^{+}$ $\mathrm{T}$ cells, to deliver a Treg and graft versus leukemia $(\mathrm{GvL})$ effect in vivo, with no adverse or aggressive GvHD effects reported as a direct consequence (Edinger and Hoffmann, 2011). Further in vivo studies are required to understand the real risk of donorspecific Treg infusion in cell therapy.

Another potential limitation of Treg therapy is assessing its capacity to control alloreactive memory. Memory $\mathrm{T}$ cell responses naturally provide rapid and potent $\mathrm{T}$ cell immunity and are a barrier to most transplantation tolerance induction strategies (Lakkis and Sayegh, 2003). Although Tregs have been demonstrated to work extremely effectively at inducing transplantation tolerance in murine models, very few have examined the capacity of Tregs to primed T cell responses (Marshall et al., 1996), to inhibit allograft rejection. Studying the efficacy of Tregs in experimental rodent systems and models cannot be accurately assessed due to the absence of a memory $\mathrm{T}$ cell pool, the importance of which has recently been demonstrated in a study correlating the presence or frequency of pre-existing $\mathrm{T}$ cell memory cells in non-human primates, with graft rejection (Nadazdin et al., 2011). The ability of Tregs to regulate memory $\mathrm{T}$ cell responses has been shown to be limited compared to naïve $\mathrm{T}$ cells when applied at the same ratio of Tregs to effectors cells (Yang et al.,

\section{REFERENCES}

Adams, A. B., and Newell, K. A. (2012). B cells in clinical transplantation tolerance. Semin. Immunol. 24, 92-95.

Afzali, B., Lechler, R. I., and Hernandez-Fuentes, M. P. (2007). Allorecognition and the alloresponse: clinical implications. Tissue Antigens 69, 545-556.

Afzali, B., Mitchell, P. J., Scotta, C., Canavan, J., Edozie, F. C., Fazekasova, H., Lord, G. M., John, S., Barber, L. D., HernandezFuentes, M. P., Lechler, R. I., and Lombardi, G. (2011). Relative resistance of human CD4(+) memory $\mathrm{T}$ cells to suppression by $\mathrm{CD} 4(+)$ CD25(+) regulatory T cells. Am. J. Transplant. 11, 1734-1742.

Akl, A., Jones, N. D., Rogers, N., Bakr, M. A., Mostafa, A., El Shehawy El, M., Ghoneim, M. A., and Wood, K.

2007; Afzali et al., 2011), which has important implications for the timing at which Treg therapy may need to be applied as preexisting alloreactive memory $\mathrm{T}$ cells may otherwise be stimulated by the transplanted organ to provoke an aggressive alloimmune response (Brook et al., 2006). Treg therapy may need to be applied in concert or in succession to immunosuppression to efficiently overcome donor-specific memory T-cell responses, as recently demonstrated by Yamada et al. using a presensitised non-human primate model of combined renal allograft and mixed chimerism, to induce transplantation tolerance (Yamada et al., 2012). The humanized mouse also represents a useful tool which can be engineered as a clinically relevant model of human graft rejection to study human Treg function (Shultz et al., 2007; Nadig et al., 2010; Sagoo et al., 2011). By reconstituting mice with human PBMCs, human immune subsets, replete with memory compartments can be established to permit an assessment of the capacity of human Tregs to regulate memory immune subsets or processes in order to achieve transplantation tolerance. It may also allow a more comprehensive evaluation of the immunoregulatory effects of Tregs on a more complete spectrum of functional human immunity, such as priming of indirect alloresponses and B cell mediated alloimmunity.

In summary, review of experimental and clinical data on transplantation tolerance support the use of donor-specific Treg therapy for establishing immunological tolerance in the clinc, in particular, Tregs with indirect allospecificity. Although current studies lack a clear demonstration of the comparative efficacy of Tregs with either direct or indirect allospecificity, there is strong evidence for an integral role of Tregs in establishing tolerance, although their contribution toward maintaining the stable tolerant state is unclear, and requires further investigation. Treg cell therapy may, therefore, be envisaged as being administered early during the post-transplantation period to accelerate the generation of other associated immunoregulatory processes that act toward maintaining stable immunological graft acceptance.

Ashour, H. M., and Niederkorn, J. Y. (2006). Peripheral tolerance via the anterior chamber of the eye: role of B cells in MHC class I and II antigen presentation. J. Immunol. 176, 5950-5957.

Auchincloss, H. Jr., Lee, R., Shea, S., Markowitz, J. S., Grusby, M. J., and Glimcher, L. H. (1993). The role of "indirect" recognition in initiating rejection of skin grafts from major histocompatibility complex class II-deficient mice. Proc. Natl. Acad. Sci. U.S.A. 90, 3373-3377.

Baan, C. C., Velthuis, J. H., Van Gurp, E. A., Mol, W. M., Klepper, M., Ijzermans, J. N., and Weimar, W. (2007). Functional CD25(bright+) alloresponsive $\mathrm{T}$ cells in fully immunosuppressed renal allograft recipients. Clin. Transplant. 21, $63-71$.
Baker, R. J., Hernandez-Fuentes, M. P., Brookes, P. A., Chaudhry, A. N., Cook, H. T., and Lechler, R. I. (2001a). Loss of direct and maintenance of indirect alloresponses in renal allograft recipients: implications for the pathogenesis of chronic allograft nephropathy. J. Immunol. 167, 7199-7206.

Baker, R. J., Hernandez-Fuentes, M. P., Brookes, P. A., Chaudhry, A. N., and Lechler, R. I. (2001b). The role of the allograft in the induction of donor-specific T cell hyporesponsiveness. Transplantation 72, 480-485.

Battaglia, M., Gregori, S., Bacchetta, R., and Roncarolo, M. G. (2006). Tr1 cells: from discovery to their clinical application. Semin. Immunol. 18, 120-127.

Origin of regulatory $\mathrm{T}$ cells with known specificity for antigen. Nat. Immunol. 3, 756-763.
Benitez, F., and Najafian, N. (2008). Novel noninvasive assays to predict 
transplantation rejection and tolerance: enumeration of cytokineproducing alloreactive T cells. Clin. Lab. Med. 28, 365-373, v.

Berard, M., and Tough, D. F. (2002). Qualitative differences between naive and memory $\mathrm{T}$ cells. Immunology 106, 127-138.

Bestard, O., Cruzado, J. M., Mestre, M., Caldes, A., Bas, J., Carrera, M., Torras, J., Rama, I., Moreso, F., Seron, D., and Grinyo, J. M. (2007). Achieving donor-specific hyporesponsiveness is associated with $\mathrm{FOXP}^{+}$regulatory $\mathrm{T}$ cell recruitment in human renal allograft infiltrates. J. Immunol. 179, 4901-4909.

Braudeau, C., Racape, M., Giral, M., Louis, S., Moreau, A., Berthelot, L., Heslan, M., Ashton-Chess, J., Soulillou, J. P., and Brouard, S. (2007). Variation in numbers of $\mathrm{CD}^{+}{ }^{+} \mathrm{CD} 25^{\text {high }} \mathrm{FOXP}^{+}{ }^{+} \mathrm{T}$ cells with normal immuno-regulatory properties in long-term graft outcome. Transpl. Int. 20, 845-855.

Brennan, T. V., Jaigirdar, A., Hoang, V., Hayden, T., Liu, F. C., Zaid, H., Chang, C. K., Bucy, R. P., Tang, Q., and Kang, S. M. (2009). Preferential priming of alloreactive $\mathrm{T}$ cells with indirect reactivity. Am. J. Transplant. 9, 709-718.

Brook, M. O., Wood, K. J., and Jones, N. D. (2006). The impact of memory $\mathrm{T}$ cells on rejection and the induction of tolerance. Transplantation 82, 1-9.

Brown, K., Sacks, S. H., and Wong, W. (2008). Extensive and bidirectional transfer of major histocompatibility complex class II molecules between donor and recipient cells in vivo following solid organ transplantation. FASEB J. 22, 3776-3784.

Brown, K., Sacks, S. H., and Wong, W. (2011). Coexpression of donor peptide/recipient MHC complex and intact donor MHC: evidence for a link between the direct and indirect pathways. Am. J. Transplant. 11, 826-831.

Brunstein, C. G., Fuchs, E. J., Carter, S. L., Karanes, C., Costa, L. J., Wu, J., Devine, S. M., Wingard, J. R., Aljitawi, O. S., Cutler, C. S., Jagasia, M. H., Ballen, K. K., Eapen, M., and O'Donnell, P. V. (2011). Alternative donor transplantation after reduced intensity conditioning: results of parallel phase 2 trials using partially HLA-mismatched related bone marrow or unrelated double umbilical cord blood grafts. Blood 118, 282-288.

Burlingham, W. J., Love, R. B., Jankowska-Gan, E., Haynes, L. D., Xu, Q., Bobadilla, J. L., Meyer, K.
C., Hayney, M. S., Braun, R. K., Greenspan, D. S., Gopalakrishnan, B., Cai, J., Brand, D. D., Yoshida, S., Cummings, O. W., and Wilkes, D. S. (2007). IL-17-dependent cellular immunity to collagen type $\mathrm{V}$ predisposes to obliterative bronchiolitis in human lung transplants. J. Clin. Invest. 117, 3498-3506.

Callaghan, C. J., Rouhani, F. J., Negus, M. C., Curry, A. J., Bolton, E. M., Bradley, J. A., and Pettigrew, G. J. (2007). Abrogation of antibodymediated allograft rejection by regulatory CD4 $\mathrm{T}$ cells with indirect allospecificity. J. Immunol. 178, 2221-2228.

Chadha, R., Heidt, S., Jones, N. D., and Wood, K. J. (2011). Th17, contributors to allograft rejection and a barrier to the induction of transplantation tolerance? Transplantation 91, 939-945.

Chen, Z. K., Cobbold, S. P., Waldmann, H., and Metcalfe, S. (1996). Amplification of natural regulatory immune mechanisms for transplantation tolerance. Transplantation 62 , 1200-1206.

Chiffoleau, E., Beriou, G., Dutartre, P. Usal, C., Soulillou, J. P., and Cuturi, M. C. (2002). Role for thymic and splenic regulatory $\mathrm{CD}^{+} \mathrm{T}$ cells induced by donor dendritic cells in allograft tolerance by LF150195 treatment. J. Immunol. 168 5058-5069.

Ciubotariu, R., Liu, Z., Colovai, A. I. Ho, E., Itescu, S., Ravalli, S., Hardy, M. A., Cortesini, R., Rose, E. A., and Suciu-Foca, N. (1998). Persistent allopeptide reactivity and epitope spreading in chronic rejection of organ allografts. J. Clin. Invest. 101, 398-405.

Cobbold, S., and Waldmann, H. (1998). Infectious tolerance. Curr. Opin. Immunol. 10, 518-524.

Colvin, R. B. (2007). Antibodymediated renal allograft rejection: diagnosis and pathogenesis. J. Am. Soc. Nephrol. 18, 1046-1056.

Conlon, T. M., Saeb-Parsy, K., Cole, J. L., Motallebzadeh, R., Qureshi, M. S., Rehakova, S., Negus, M. C., Callaghan, C. J., Bolton, E. M., Bradley, J. A., and Pettigrew, G. J. (2012). Germinal center alloantibody responses are mediated exclusively by indirect-pathway CD4 T follicular helper cells. J. Immunol. 188, 2643-2652.

De Haan, A., Van Der Gun, I., Hepkema, B. G., De Boer, W. J., Van Der Bij, W., De Leij, L. F., and Prop, J. (2000). Decreased donor-specific cytotoxic $\mathrm{T}$ cell precursor frequencies one year after clinical lung transplantation do not reflect transplantation tolerance: a comparison of lung transplant recipients with or without bronchiolitis obliterans syndrome. Transplantation 69, 1434-1439.

Di Ianni, M., Falzetti, F., Carotti, A., Terenzi, A., Castellino, F., Bonifacio, E., Del Papa, B., Zei, T., Ostini, R. I., Cecchini, D., Aloisi, T., Perruccio, K., Ruggeri, L., Balucani, C., Pierini, A., Sportoletti, P., Aristei, C., Falini, B., Reisner, Y., Velardi, A., Aversa, F., and Martelli, M. F. (2011). Tregs prevent GVHD and promote immune reconstitution in HLAhaploidentical transplantation. Blood 117, 3921-3928.

Dijke, I. E., Korevaar, S. S., Caliskan, K., Balk, A. H., Maat, A. P., Weimar, W., and Baan, C. C. (2009). Inadequate immune regulatory function of $\mathrm{CD}^{+}{ }^{+} \mathrm{CD} 25^{\text {bright }}+\mathrm{FoxP}^{+} \mathrm{T}$ cells in heart transplant patients who experience acute cellular rejection. Transplantation 87, 1191-1200.

Dijke, I. E., Weimar, W., and Baan, C. C. (2008). Regulatory T cells after organ transplantation: where does their action take place? Hum Immunol. 69, 389-398.

Eberspacher, M. L., Otto, G., Herfarth, C., and Kabelitz, D. (1994). Frequency analysis of donorreactive cytotoxic $\mathrm{T}$ lymphocyte precursors in in allograft recipients. Lack of correlation with clinical outcome. Transplantation 57, 1746-1752.

Edinger, M., and Hoffmann, P. (2011). Regulatory $\mathrm{T}$ cells in stem cell transplantation: strategies and first clinical experiences. Curr. Opin. Immunol. 23, 679-684.

Edinger, M., Hoffmann, P., Ermann, J., Drago, K., Fathman, C. G., Strober, S., and Negrin, R. S. (2003). $\mathrm{CD} 4{ }^{+} \mathrm{CD} 25^{+}$regulatory $\mathrm{T}$ cells preserve graft-versus-tumor activity while inhibiting graft-versus-host disease after bone marrow transplantation. Nat. Med. 9, 1144-1150.

Fernandes, E., Goold, H. D. Kissenpfennig, A., Malissen, B., Dyson, J., and Bennett, C. L. (2011). The role of direct presentation by donor dendritic cells in rejection of minor histocompatibility antigen-mismatched skin and hematopoietic cell grafts. Transplantation 91, 154-160.

Fischer, R. T., Turnquist, H. R., Wang, Z., Beer-Stolz, D., and Thomson, A. W. (2011). Rapamycin-conditioned, alloantigen-pulsed myeloid dendritic cells present donor MHC class I/peptide via the semi-direct pathway and inhibit survival of antigen-specific CD8(+) $\mathrm{T}$ cells in vitro and in vivo. Transpl. Immunol. 25, 20-26.

Game, D. S., Hernandez-Fuentes, M. P., Chaudhry, A. N., and Lechler, R. I. (2003). $\mathrm{CD}^{+} \mathrm{CD}^{2} 5^{+}$regulatory $\mathrm{T}$ cells do not significantly contribute to direct pathway hyporesponsiveness in stable renal transplant patients. J. Am. Soc. Nephrol. 14, 1652-1661.

Garrod, K. R., Liu, F. C., Forrest, L. E., Parker, I., Kang, S. M., and Cahalan, M. D. (2010). NK cell patrolling and elimination of donor-derived dendritic cells favor indirect alloreactivity. J. Immunol. 184, 2329-2336.

Ghobrial, I. I., Morris, A. G., and Booth, L. J. (1994). Clinical significance of in vitro donor-specific hyporesponsiveness in renal allograft recipients as demonstrated by the MLR. Transpl. Int. 7, 420-427.

Gokmen, M. R., Lombardi, G., and Lechler, R. I. (2008). The importance of the indirect pathway of allorecognition in clinical transplantation. Curr. Opin. Immunol. 20, 568-574.

Golshayan, D., Jiang, S., Tsang, J., Garin, M. I., Mottet, C., and Lechler, R. I. (2007). In vitro-expanded donor alloantigenspecific $\mathrm{CD}^{+}{ }^{+} \mathrm{CD} 25^{+}$regulatory $\mathrm{T}$ cells promote experimental transplantation tolerance. Blood 109, 827-835.

Golshayan, D., Wyss, J. C., Abulker, C. W., Schaefer, S. C., Lechler, R. I., Lehr, H. A., and Pascual, M. (2009). Transplantation tolerance induced by regulatory $\mathrm{T}$ cells: in vivo mechanisms and sites of action. Int. Immunopharmacol. 9, 683-688.

Graca, L., Cobbold, S. P., and Waldmann, H. (2002). Identification of regulatory $\mathrm{T}$ cells in tolerated allografts. J. Exp. Med. 195, 1641-1646.

Gras, S., Kjer-Nielsen, L., Chen, Z., Rossjohn, J., and McCluskey, J. (2011). The structural bases of direct T-cell allorecognition: implications for T-cell-mediated transplant rejection. Immunol. Cell Biol. 89, 388-395.

Gupta, S., Balasubramanian, S., Thornley, T. B., Strom, T. B., and Kenny, J. J. (2011). Direct pathway T-cell alloactivation is more rapid than indirect pathway alloactivation. Transplantation 91, e65-e67.

Hamano, K., Rawsthorne, M. A., Bushell, A. R., Morris, P. J., and Wood, K. J. (1996). Evidence that the continued presence of the organ graft and not peripheral donor microchimerism is essential for maintenance of tolerance to 
alloantigen in vivo in anti-CD4 treated recipients. Transplantation 62, 856-860.

Hara, M., Kingsley, C. I., Niimi, M., Read, S., Turvey, S. E., Bushell, A. R., Morris, P. J., Powrie, F., and Wood, K. J. (2001). IL-10 is required for regulatory $\mathrm{T}$ cells to mediate tolerance to alloantigens in vivo. J. Immunol. 166, 3789-3796.

Haynes, L. D., Jankowska-Gan, E., Sheka, A., Keller, M. R., HernandezFuentes, M. P., Lechler, R. I., Seyfert-Margolis, V., Turka, L. A., Newell, K. A., and Burlingham, W. J. (2012). Donor-specific indirect pathway analysis reveals a B-cell-independent signature which reflects outcomes in kidney transplant recipients. Am. J. Transplant. 12, 640-648.

Hendrikx, T. K., Van Gurp, E. A., Sewgobind, V. D., Mol, W. M., Schoordijk, W., Klepper, M., Velthuis, J. H., Geel, A., Ijzermans, J. N., Weimar, W., and Baan, C. C. (2009). Generation of donorspecific regulatory $\mathrm{T}$-cell function in kidney transplant patients. Transplantation 87, 376-383.

Herman, S., Krenbek, D., Klimas, M., Bonelli, M., Steiner, C. W., Pietschmann, P., Smolen, J. S., and Scheinecker, C. (2012). Regulatory $\mathrm{T}$ cells form stable and long-lasting cell cluster with myeloid dendritic cells (DC). Int. Immunol. 7, 417-426.

Hernandez-Fuentes, M. P., and Lechler, R. I. (2005). Chronic graft loss. Immunological and nonimmunological factors. Contrib. Nephrol. 146, 54-64.

Herrera, O. B., Golshayan, D., Tibbott, R., Salcido Ochoa, F., James, M. J., Marelli-Berg, F. M., and Lechler, R. I. (2004). A novel pathway of alloantigen presentation by dendritic cells. J. Immunol. 173, 4828-4837.

Heslan, J. M., Beriou, G., Le Luduec, J. B., Guillonneau, C., Anegon, I., Soulillou, J. P., Cuturi, M. C., and Chiffoleau, E. (2005). Accumulation of $\mathrm{T}$ cells with potent regulatory properties and restricted Vbeta7-TCR rearrangements in tolerated allografts. Transplantation 80, 1476-1484.

Hippen, K. L., Riley, J. L., June, C. H., and Blazar, B. R. (2011). Clinical perspectives for regulatory $\mathrm{T}$ cells in transplantation tolerance. Semin. Immunol. 23, 462-468.

Honjo, K., Xu, X., and Bucy, R. P. (2004). $\mathrm{CD}^{+}$T-cell receptor transgenic $\mathrm{T}$ cells alone can reject vascularized heart transplants through the indirect pathway of alloantigen recognition. Transplantation 77, 452-455.

Hornick, P. I., Mason, P. D., Baker, R. J., Hernandez-Fuentes, M., Frasca, L., Lombardi, G., Taylor, K., Weng, L., Rose, M. L., Yacoub, M. H., Batchelor, R., and Lechler, R. I. (2000). Significant frequencies of $\mathrm{T}$ cells with indirect anti-donor specificity in heart graft recipients with chronic rejection. Circulation 101, 2405-2410.

Hornick, P. I., Mason, P. D., Yacoub, M. H., Rose, M. L., Batchelor, R., and Lechler, R. I. (1998). Assessment of the contribution that direct allorecognition makes to the progression of chronic cardiac transplant rejection in humans. Circulation 97, 1257-1263.

Hsieh, C.-S., Liang, Y., Tyznik, A. J., Self, S. G., Liggitt, D., and Rudensky, A. Y. (2004). Recognition of the Peripheral Self by Naturally Arising CD25 ${ }^{+} \mathrm{CD}^{+} \mathrm{T}$ Cell Receptors. Immunity 21, 267-277.

Hu, H., Robertus, M., De Jonge, N., Gmelig-Meyling, F. H., Van Der Meulen, A., Schuurman, H. J., Doornewaard, H., Van Prooijen, H. C., and De Weger, R. A. (1994). Reduction of donor-specific cytotoxic $\mathrm{T}$ lymphocyte precursors in peripheral blood of allografted heart recipients. Transplantation 58, 1263-1268.

Iwata, Y., Matsushita, T., Horikawa, M., Dilillo, D. J., Yanaba, K., Venturi, G. M., Szabolcs, P. M., Bernstein, S. H., Magro, C. M., Williams, A. D., Hall, R. P., St Clair, E. W., and Tedder, T. F. (2011). Characterization of a rare IL-10-competent B-cell subset in humans that parallels mouse regulatory B10 cells. Blood 117, 530-541.

Jang, E., Cho, W. S., Cho, M. L., Park, H. J., Oh, H. J., Kang, S. M., Paik, D. J., and Youn, J. (2011). Foxp $^{+}$regulatory $\mathrm{T}$ cells control humoral autoimmunity by suppressing the development of longlived plasma cells. J. Immunol. 186, 1546-1553.

Janssens, W., Carlier, V., Wu, B., Vanderelst, L., Jacquemin, M. G., and Saint-Remy, J. M. (2003). $\mathrm{CD} 4{ }^{+} \mathrm{CD} 25^{+} \mathrm{T}$ cells lyse antigenpresenting $B$ cells by Fas-Fas ligand interaction in an epitopespecific manner. J. Immunol. 171, 4604-4612.

Jiang, S., Tsang, J., and Lechler, R. I. (2006). Adoptive cell therapy using in vitro generated human $\mathrm{CD}^{+}{ }^{+} \mathrm{CD} 25^{+}$regulatory $\mathrm{t}$ cells with indirect allospecificity to promote donor-specific transplantation tolerance. Transplant. Proc. 38, 3199-3201.
Joffre, O., Santolaria, T., Calise, D., Al Saati, T., Hudrisier, D., Romagnoli, P., and Van Meerwijk, J. P. (2008). Prevention of acute and chronic allograft rejection with $\mathrm{CD}^{+}{ }^{+} \mathrm{CD} 25^{+}$Foxp $^{+}$regulatory $\mathrm{T}$ lymphocytes. Nat. Med. 14, 88-92.

Jones, N. D., Carvalho-Gaspar, M., Luo, S., Brook, M. O., Martin, L., and Wood, K. J. (2006). Effector and memory $\mathrm{CD}^{+}{ }^{+} \mathrm{T}$ cells can be generated in response to alloantigen independently of $\mathrm{CD}^{+}{ }^{+} \mathrm{T}$ cell help. J. Immunol. 176, 2316-2323.

Jordan, M. S., Boesteanu, A., Reed, A J., Petrone, A. L., Holenbeck, A. E., Lerman, M. A., Naji, A., and Caton, A. J. (2001). Thymic selection of $\mathrm{CD}^{+}{ }^{+} \mathrm{CD} 25^{+}$regulatory $\mathrm{T}$ cells induced by an agonist selfpeptide. Nat. Immunol. 2, 301-306.

Jurcevic, S., Chandler, P., Sacks, S. H., and Simpson, E. (2001). Rapid rejection of HLA-A2 transgenic skin graft due to indirect allorecognition. Transplantation 72, 994-997.

Kawai, T., Cosimi, A. B., Spitzer, T. R. Tolkoff-Rubin, N., Suthanthiran, M., Saidman, S. L., Shaffer, J., Preffer, F. I., Ding, R., Sharma, V., Fishman, J. A., Dey, B., Ko, D. S. Hertl, M., Goes, N. B., Wong, W. Williams, W. W. Jr., Colvin, R. B. Sykes, M., and Sachs, D. H. (2008). HLA-mismatched renal transplantation without maintenance immunosuppression. N. Engl. J. Med. 358, 353-361.

Kishimoto, K., Yuan, X., Auchincloss, H. Jr., Sharpe, A. H., Mandelbrot, D. A., and Sayegh, M. H. (2004) Mechanism of action of donorspecific transfusion in inducing tolerance: role of donor $\mathrm{MHC}$ molecules, donor co-stimulatory molecules, and indirect antigen presentation. J. Am. Soc. Nephrol. 15, 2423-2428.

Ko, S., Deiwick, A., Dinkel, A. Wonigeit, K., and Schlitt, H. J. (1999a). Functional relevance of donor-derived hematopoietic microchimerism only for induction but not for maintenance of allograft acceptance. Transplant. Proc. 31 920-921.

Ko, S., Deiwick, A., Jager, M. D., Dinkel, A., Rohde, F., Fischer, R., Tsui, T. Y., Rittmann, K. L., Wonigeit, K., and Schlitt, H. J. (1999b). The functional relevance of passenger leukocytes and microchimerism for heart allograft acceptance in the rat. Nat. Med. 5, 1292-1297.

Kreijveld, E., Koenen, H. J., Klasen, I. S., Hilbrands, L. B., and Joosten, I. (2007). Following anti-CD25 treatment, a functional $\mathrm{CD} 4{ }^{+} \mathrm{CD} 25^{+}$ regulatory $\mathrm{T}$-cell pool is present in renal transplant recipients. Am. J. Transplant. 7, 249-255.

Laffont, S., Coudert, J. D., Garidou, L., Delpy, L., Wiedemann, A., Demur, C., Coureau, C., and Guery, J. C. (2006). $\mathrm{CD}^{+}$T-cell-mediated killing of donor dendritic cells prevents alloreactive $\mathrm{T}$ helper type2 responses in vivo. Blood 108, 2257-2264

Laffont, S., Seillet, C., Ortaldo, J., Coudert, J. D., and Guery, J. C. (2008). Natural killer cells recruited into lymph nodes inhibit alloreactive T-cell activation through perforin-mediated killing of donor allogeneic dendritic cells. Blood 112, 661-671.

Lakkis, F. G., and Sayegh, M. H. (2003). Memory T cells: a hurdle to immunologic tolerance. J. Am. Soc Nephrol. 14, 2402-2410.

Lamb, K. E., Lodhi, S., and MeierKriesche, H. U. (2010). Long-term renal allograft survival in the United States: a critical reappraisal. Am. J. Transplant. 3, 450-462.

Larsen, C. P., Austyn, J. M., and Morris, P. J. (1990). The role of graft-derived dendritic leukocytes in the rejection of vascularized organ allografts. Recent findings on the migration and function of dendritic leukocytes after transplantation. Ann. Surg. 212, 308-315; discussion 316-307.

Le Texier, L., Thebault, P., Lavault, A., Usal, C., Merieau, E., Quillard, T., Charreau, B., Soulillou, J. P., Cuturi, M. C., Brouard, S., and Chiffoleau, E. (2011). Long-term allograft tolerance is characterized by the accumulation of B cells exhibiting an inhibited profile. Am. J. Transplant. 11, 429-438.

Lechler, R. I., and Batchelor, J. R. (1982a). Immunogenicity of retransplanted rat kidney allografts. Effect of inducing chimerism in the first recipient and quantitative studies on immunosuppression of the second recipient. J. Exp. Med. 156, 1835-1841.

Lechler, R. I., and Batchelor, J. R. (1982b). Restoration of immunogenicity to passenger cell-depleted kidney allografts by the addition of donor strain dendritic cells. J. Exp. Med. 155, 31-41.

Lechler, R. I., Heaton, T., Barber, L., Bal, V., Batchelor, J. R., and Lombardi, G. (1992). Molecular mimicry by major histocompatibility complex molecules and peptides accounts for some alloresponses. Immunol. Lett. 34, 63-69.

Lee, R. S., Grusby, M. J., Glimcher, L. H., Winn, H. J., and Auchincloss, H. Jr. (1994). Indirect recognition by helper cells can induce 
donor-specific cytotoxic T lymphocytes in vivo. J. Exp. Med. 179, 865-872.

LeGuern, C. (2004). Potential role of major histocompatibility complex class II peptides in regulatory tolerance to vascularized grafts. Transplantation 77, S35-S37.

LeGuern, C., Akiyama, Y., Germana, S., Tanaka, K., Fernandez, L., Iwamoto, Y., Houser, S., and Benichou, G. (2010). Intracellular MHC class II controls regulatory tolerance to allogeneic transplants. J. Immunol. 184, 2394-2400.

Leventhal, J., Abecassis, M., Miller, J., Gallon, L., Ravindra, K., Tollerud, D. J., King, B., Elliott, M. J., Herzig, G., Herzig, R., and Ildstad, S. T. (2012). Chimerism and tolerance Without GVHD or engraftment syndrome in HLA-mismatched combined kidney and hematopoietic Stem cell transplantation. Sci. Transl. Med. 4, 124ra128.

Li, Y., Koshiba, T., Yoshizawa, A., Yonekawa, Y., Masuda, K., Ito, A., Ueda, M., Mori, T., Kawamoto, H., Tanaka, Y., Sakaguchi, S., Minato, N., Wood, K. J., and Tanaka, K. (2004). Analyses of peripheral blood mononuclear cells in operational tolerance after pediatric living donor liver transplantation. Am. J. Transplant. 4, 2118-2125.

Li, Y., Zhao, X., Cheng, D., Haga, H., Tsuruyama, T., Wood, K., Sakaguchi, S., Tanaka, K., Uemoto, S., and Koshiba, T. (2008). The presence of Foxp3 expressing $\mathrm{T}$ cells within grafts of tolerant human liver transplant recipients. Transplantation 86, 1837-1843.

Lim, H. W., Hillsamer, P., Banham, A. H., and Kim, C. H. (2005). Cutting edge: direct suppression of $\mathrm{B}$ cells by $\mathrm{CD} 4{ }^{+} \mathrm{CD} 25^{+}$regulatory $\mathrm{T}$ cells. J. Immunol. 175, 4180-4183.

Lim, H. W., Hillsamer, P., and Kim, C. H. (2004). Regulatory T cells can migrate to follicles upon $\mathrm{T}$ cell activation and suppress GCTh cells and GC-Th cell-driven B cell responses. J. Clin. Invest. 114, 1640-1649.

Liu, W., Putnam, A. L., Xu-Yu, Z., Szot, G. L., Lee, M. R., Zhu, S., Gottlieb, P. A., Kapranov, P., Gingeras, T. R., Fazekas De St. Groth, B., Clayberger, C., Soper, D. M., Ziegler, S. F., and Bluestone, J. A. (2006). CD127 expression inversely correlates with FoxP3 and suppressive function of human $\mathrm{CD}^{+} \mathrm{T}$ reg cells. J. Exp. Med. 203, 1701-1711.

Lodhi, S. A., Lamb, K. E., and MeierKriesche, H. U. (2011). Solid organ allograft survival improvement in the United States: the long-term does not mirror the dramatic shortterm success. Am. J. Transplant. 11, 1226-1235.

Lombardi, G., Barber, L., Sidhu, S., Batchelor, J. R., and Lechler, R. I. (1991). The specificity of alloreactive $\mathrm{T}$ cells is determined by MHC polymorphisms which contact the $\mathrm{T}$ cell receptor and which influence peptide binding. Int. Immunol. 3, 769-775.

Lombardi, G., Sagoo, P., Scotta, C., Fazekasova, H., Smyth, L., Tsang, J., Afzali, B., and Lechler, R. (2011). Cell therapy to promote transplantation tolerance: a winning strategy? Immunotherapy 3, 28-31.

Lombardi, G., Sidhu, S., Daly, M., Batchelor, J. R., Makgoba, W., and Lechler, R. I. (1990). Are primary alloresponses truly primary? Int. Immunol. 2, 9-13.

London, C. A., Lodge, M. P., and Abbas, A. K. (2000). Functional responses and costimulator dependence of memory $\mathrm{CD}^{+} \mathrm{T}$ cells. J. Immunol. 164, 265-272.

Loonen, L., Vaessen, L., Balk, A., Groeneveld, K., Mochtar, B., Jutte, N., Claas, F., and Weimar, W. (1994). Long-term survival of heart grafts in the presence of donorspecific cytotoxic T-cell precursors (CTLp) in the peripheral blood. Transpl. Int. 7, S596-S598.

Louis, S., Braudeau, C., Giral, M., Dupont, A., Moizant, F., Robillard, N., Moreau, A., Soulillou, J. P., and Brouard, S. (2006). Contrasting $\mathrm{CD}_{25 h i C D}{ }^{+} \mathrm{T}$ cells/FOXP3 patterns in chronic rejection and operational drug-free tolerance. Transplantation 81, 398-407.

Lund, F. E., and Randall, T. D. (2010). Effector and regulatory $\mathrm{B}$ cells: modulators of CD4(+) T cell immunity. Nat. Rev. Immunol. 10, 236-247.

Macedo, C., Orkis, E. A., Popescu, I., Elinoff, B. D., Zeevi, A., Shapiro, R., Lakkis, F. G., and Metes, D. (2009). Contribution of naive and memory T-cell populations to the human alloimmune response. Am. J. Transplant. 9, 2057-2066.

Mahnke, K., Bedke, T., and Enk, A. H. (2007). Regulatory conversation between antigen presenting cells and regulatory $\mathrm{T}$ cells enhance immune suppression. Cell. Immunol. 250, 1-13.

Marelli-Berg, F. M., Hargreaves, R. E., Carmichael, P., Dorling, A., Lombardi, G., and Lechler, R. I. (1996). Major histocompatibility complex class II-expressing endothelial cells induce allospecific nonresponsiveness in naive $\mathrm{T}$ cells. J. Exp. Med. 183, 1603-1612.
Marshall, S. E., Cobbold, S. P., Davies, J. D., Martin, G. M., Phillips, J. M., and Waldmann, $\mathrm{H}$ (1996). Tolerance and suppression in a primed immune system. Transplantation 62, 1614-1621.

Martinez-Llordella, M., Lozano, J. J., Puig-Pey, I., Orlando, G., Tisone, G., Lerut, J., Benitez, C., Pons, J. A., Parrilla, P., Ramirez, P., Bruguera, M., Rimola, A., and Sanchez-Fueyo, A. (2008). Using transcriptional profiling to develop a diagnostic test of operational tolerance in liver transplant recipients. J. Clin. Invest. 118, 2845-2857.

Martinez-Llordella, M., Puig-Pey, I., Orlando, G., Ramoni, M., Tisone, G., Rimola, A., Lerut, J., Latinne, D., Margarit, C., Bilbao, I., Brouard, S., Hernandez-Fuentes, M., Soulillou, J. P., and Sanchez-Fueyo, A. (2007). Multiparameter immune profiling of operational tolerance in liver transplantation. Am. J. Transplant. 7, 309-319.

Mason, P. D., Robinson, C. M., and Lechler, R. I. (1996). Detection of donor-specific hyporesponsiveness following late failure of human renal allografts. Kidney Int. 50, 1019-1025.

Mauri, C., and Blair, P. A. (2010). Regulatory B cells in autoimmunity: developments and controversies. Nat. Rev. Rheumatol. 6, 636-643.

Meier-Kriesche, H. U., Schold, J. D., and Kaplan, B. (2004a). Longterm renal allograft survival: have we made significant progress or is it time to rethink our analytic and therapeutic strategies? Am. J. Transplant. 4, 1289-1295.

Meier-Kriesche, H. U., Schold, J. D., Srinivas, T. R., and Kaplan, B. (2004b). Lack of improvement in renal allograft survival despite a marked decrease in acute rejection rates over the most recent era. Am. J. Transplant. 4, 378-383.

Merkenschlager, M., and Beverley, P. C. (1989). Evidence for differential expression of CD45 isoforms by precursors for memorydependent and independent cytotoxic responses: human CD8 memory CTLp selectively express CD45RO (UCHL1). Int. Immunol. 1, 450-459.

Mestre, M., Massip, E., Bas, J., Alsina, J., Romeu, A., Castelao, A. M., Buendia, E., and Grinyo, J. M. (1996). Longitudinal study of the frequency of cytotoxic $\mathrm{T}$ cell precursors in kidney allograft recipients. Clin. Exp. Immunol. 104, 108-114.

Misra, N., Bayry, J., Lacroix-Desmazes, S., Kazatchkine, M. D., and Kaveri,
S. V. (2004). Cutting edge: human $\mathrm{CD} 4{ }^{+} \mathrm{CD} 25^{+} \mathrm{T}$ cells restrain the maturation and antigen-presenting function of dendritic cells. $J$. Immunol. 172, 4676-4680.

Miyara, M., Yoshioka, Y., Kitoh, A., Shima, T., Wing, K., Niwa, A., Parizot, C., Taflin, C., Heike, T., Valeyre, D., Mathian, A., Nakahata, T., Yamaguchi, T., Nomura, T., Ono, M., Amoura, Z., Gorochov, G., and Sakaguchi, S. (2009). Functional delineation and differentiation dynamics of human $\mathrm{CD}^{+} \mathrm{T}$ cells expressing the FoxP3 transcription factor. Immunity 30, 899-911.

Nadazdin, O., Boskovic, S., Murakami, T., Tocco, G., Smith, R. N., Colvin, R. B., Sachs, D. H., Allan, J., Madsen, J. C., Kawai, T., Cosimi, A. B., and Benichou, G. (2011). Host alloreactive memory $\mathrm{T}$ cells influence tolerance to kidney allografts in nonhuman primates. Sci. Transl. Med. 3, 86ra51.

Nadig, S. N., Wieckiewicz, J., Wu, D. C., Warnecke, G., Zhang, W., Luo, S., Schiopu, A., Taggart, D. P., and Wood, K. J. (2010). In vivo prevention of transplant arteriosclerosis by ex vivo-expanded human regulatory T cells. Nat. Med. 16, 809-813.

Nafady-Hego, H., Li, Y., Ohe, H., Zhao, X., Satoda, N., Sakaguchi, S., Wood, K., Uemoto, S., and Koshiba, T. (2010). The generation of donorspecific $\mathrm{CD}^{+} \mathrm{CD} 25^{+}+\mathrm{CD} 45 \mathrm{RA}^{+}$ naive regulatory $\mathrm{T}$ cells in operationally tolerant patients after pediatric living-donor liver transplantation. Transplantation 90, 1547-1555.

Nepom, G. T., St Clair, E. W., and Turka, L. A. (2011). Challenges in the pursuit of immune tolerance. Immunol. Rev. 241, 49-62.

Newell, K. A., Asare, A., Kirk, A. D., Gisler, T. D., Bourcier, K., Suthanthiran, M., Burlingham, W. J., Marks, W. H., Sanz, I., Lechler, R. I., Hernandez-Fuentes, M. P., Turka, L. A., and Seyfert-Margolis, V. L. (2010). Identification of a B cell signature associated with renal transplant tolerance in humans. J. Clin. Invest. 120, 1836-1847.

Niederkorn, J. Y., and Mayhew, E. (2002). Phenotypic analysis of oral tolerance to alloantigens: evidence that the indirect pathway of antigen presentation is involved. Transplantation 73, 1493-1500.

Niimi, M., Shirasugi, N., Ikeda, Y., and Wood, K. J. (2001). Oral antigen induces allograft survival by linked suppression via the indirect pathway. Transplant. Proc. 33, 81.

Noorchashm, H., Reed, A. J., Rostami, S. Y., Mozaffari, R., Zekavat, G. 
Koeberlein, B., Caton, A. J., and Naji, A. (2006). B cell-mediated antigen presentation is required for the pathogenesis of acute cardiac allograft rejection. J. Immunol. 177, 7715-7722.

Oei, F. B., Welters, M. J., Knoop, C. J., Vaessen, L. M., Stegmann, A. P., Weimar, W., and Bogers, A. J. (2000). Circulating donor-specific cytotoxic $\mathrm{T}$ lymphocytes with high avidity for donor human leukocyte antigens in pediatric and adult cardiac allograft valved conduit recipients. Eur. J. Cardiothorac. Surg. 18, 466-472.

Okumi, M., Fishbein, J. M., Griesemer, A. D., Gianello, P. R., Hirakata, A., Nobori, S., Moran, S., SamelsonJones, E., Shimizu, A., Sachs, D. H., and Yamada, K. (2008). Role of persistence of antigen and indirect recognition in the maintenance of tolerance to renal allografts. Transplantation 85, 270-280.

Pallier, A., Hillion, S., Danger, R., Giral, M., Racape, M., Degauque, N., Dugast, E., Ashton-Chess, J., Pettre, S., Lozano, J. J., Bataille, R., Devys, A., Cesbron-Gautier, A., Braudeau, C., Larrose, C., Soulillou, J. P., and Brouard, S. (2010). Patients with drug-free long-term graft function display increased numbers of peripheral B cells with a memory and inhibitory phenotype. Kidney Int. 78, 503-513.

Pasquet, L., Joffre, O., Santolaria, T., and Van Meerwijk, J. (2011). Hematopoietic chimerism and transplantation tolerance: a role for regulatory $\mathrm{T}$ cells. Front. Immunol. 2:80. doi: 10.3389/fimmu.2011.00080

Perucha, E., Rebollo-Mesa, I., Sagoo, P., and Hernandez-Fuentes, M. P. (2011). Biomarkers of tolerance: searching for the hidden phenotype. Kidney Int. Sup. 1, 40-46.

Peters, J. H., Hilbrands, L. B., Koenen, H. J., and Joosten, I. (2008). Ex vivo generation of human alloantigen-specific regulatory $\mathrm{T}$ cells from CD4(pos)CD25(high) $\mathrm{T}$ cells for immunotherapy. PLoS ONE 3:e2233. doi: 10.1371/journal.pone.0002233

Poggio, E. D., Clemente, M., Riley, J., Roddy, M., Greenspan, N. S., Dejelo, C., Najafian, N., Sayegh, M. H., Hricik, D. E., and Heeger, P. S. (2004). Alloreactivity in renal transplant recipients with and without chronic allograft nephropathy. J. Am. Soc. Nephrol. 15, 1952-1960.

Pons, J. A., Revilla-Nuin, B., Baroja-Mazo, A., Ramirez, P., Martinez-Alarcon, L., SanchezBueno, F., Robles, R., Rios, A.,
Aparicio, P., and Parrilla, P. (2008). FoxP3 in peripheral blood is associated with operational tolerance in liver transplant patients during immunosuppression withdrawal. Transplantation 86, 1370-1378.

Qin, S., Cobbold, S. P., Pope, H., Elliott, J., Kioussis, D., Davies, J., and Waldmann, H. (1993). "Infectious" transplantation tolerance. Science 259, 974-977.

Ray, A., Basu, S., Williams, C. B., Salzman, N. H., and Dittel, B. N. (2012). A novel IL-10-independent regulatory role for $\mathrm{B}$ cells in suppressing autoimmunity by maintenance of regulatory $\mathrm{T}$ cells via GITR ligand. J. Immunol. 188, 3188-3198.

Riond, J., Elhmouzi, J., Hudrisier, D., and Gairin, J. E. (2007). Capture of membrane components via trogocytosis occurs in vivo during both dendritic cells and target cells encounter by CD8 $(+)$ T cells. Scand. J. Immunol. 66, 441-450.

Romagnoli, P., Hudrisier, D., and Van Meerwijk, J. P. (2002). Preferential recognition of self antigens despite normal thymic deletion of CD4(+)CD25(+) regulatory $\mathrm{T}$ cells. J. Immunol. 168, 1644-1648.

Rulifson, I. C., Szot, G. L., Palmer, E., and Bluestone, J. A. (2002). Inability to induce tolerance through direct antigen presentation. Am. J. Transplant. 2, 510-519.

Sagoo, P., Ali, N., Garg, G., Nestle, F. O., Lechler, R. I., and Lombardi, G. (2011). Human regulatory $T$ cells with alloantigen specificity are more potent inhibitors of alloimmune skin graft damage than polyclonal regulatory T cells. Sci. Transl. Med. 3, 83ra42.

Sagoo, P., Lombardi, G., and Lechler, R. I. (2008). Regulatory T cells as therapeutic cells. Curr. Opin. Organ. Transplant. 13, 645-653.

Sagoo, P., Perucha, E., Sawitzki, B., Tomiuk, S., Stephens, D. A., Miqueu, P., Chapman, S., Craciun, L., Sergeant, R., Brouard, S., Rovis, F., Jimenez, E., Ballow, A., Giral, M., Rebollo-Mesa, I., Le Moine, A., Braudeau, C., Hilton, R., Gerstmayer, B., Bourcier, K., Sharif, A., Krajewska, M., Lord, G. M., Roberts, I., Goldman, M., Wood, K. J., Newell, K., Seyfert-Margolis, V., Warrens, A. N., Janssen, U., Volk, H. D., Soulillou, J. P., HernandezFuentes, M. P., and Lechler, R. I. (2010). Development of a crossplatform biomarker signature to detect renal transplant tolerance in humans. J. Clin. Invest. 120, 1848-1861.
Sakaguchi, S. (2004). Naturally arising $\mathrm{CD}^{+}$regulatory $\mathrm{t}$ cells for immunologic self-tolerance and negative control of immune responses. Annu. Rev. Immunol. 22, 531-562.

Sakaguchi, S., and Sakaguchi, N. (2005). Regulatory $\mathrm{T}$ cells in immunologic self-tolerance and autoimmune disease. Int. Rev. Immunol. 24, 211-226.

Salama, A. D., Chaudhry, A. N. Holthaus, K. A., Mosley, K., Kalluri, R., Sayegh, M. H., Lechler, R. I., Pusey, C. D., and Lightstone, L. (2003a). Regulation by CD $25^{+}$lymphocytes of autoantigen-specific T-cell responses in Goodpasture's (anti-GBM) disease. Kidney Int. 64, 1685-1694.

Salama, A. D., Najafian, N., Clarkson, M. R., Harmon, W. E., and Sayegh, M. H. (2003b). Regulatory CD25+ $\mathrm{T}$ cells in human kidney transplant recipients. J. Am. Soc. Nephrol. 14, 1643-1651.

Sanchez-Fueyo, A., Domenig, C. M., Mariat, C., Alexopoulos, S., Zheng, X. X., and Strom, T. B. (2007). Influence of direct and indirect allorecognition pathways on $\mathrm{CD} 4{ }^{+} \mathrm{CD} 25^{+}$regulatory $\mathrm{T}$ cell function in transplantation. Transpl. Int. 20, 534-541.

Sanchez-Fueyo, A., Sandner, S., Habicht, A., Mariat, C., Kenny, J., Degauque, N., Zheng, X. X., Strom, T. B., Turka, L. A., and Sayegh, M. H. (2006). Specificity of $\mathrm{CD}^{+} \mathrm{CD}_{2} 5^{+}$regulatory $\mathrm{T}$ cell function in alloimmunity. J. Immunol. 176, 329-334.

Sawitzki, B., Schlickeiser, S., Reinke, P., and Volk, H. D. (2011). Monitoring tolerance and rejection in organ transplant recipients. Biomarkers 16(Suppl. 1), S42-S50.

Scully, R., Qin, S., Cobbold, S., and Waldmann, H. (1994). Mechanisms in CD4 antibody-mediated transplantation tolerance: kinetics of induction, antigen dependency and role of regulatory $\mathrm{T}$ cells. Eur. J. Immunol. 24, 2383-2392.

Sewgobind, V. D., Van Der Laan, L. J., Klepper, M., Ijzermans, J. N., Tilanus, H. W., Weimar, W., and Baan, C. C. (2008). Functional analysis of $\mathrm{CD}^{+} \mathrm{CD} 25$ bright $\mathrm{T}$ cells in kidney transplant patients: improving suppression of donordirected responses after transplantation. Clin. Transplant. 22, 579-586.

Shan, J., Guo, Y., Luo, L., Lu, J., Li, C., Zhang, C., Huang, Y., Feng, L., Wu, W., Long, D., Li, S., and Li, Y. (2011). Do CD ${ }^{+}$Foxp3 ${ }^{+}$Treg cells correlate with transplant outcomes: a systematic review on recipients of solid organ transplantation. Cell. Immunol. 270, 5-12.

Shevach, E. M. (2009). Mechanisms of foxp $3^{+} \mathrm{T}$ regulatory cell-mediated suppression. Immunity 30, 636-645.

Shultz, L. D., Ishikawa, F., and Greiner, D. L. (2007). Humanized mice in translational biomedical research. Nat. Rev. Immunol. 7, 118-130.

Sims, T. N., Afrouzian, M., Urmson, J., Zhu, L. F., and Halloran, P. F. (2001) The role of the class II transactivator (CIITA) in MHC class I and II regulation and graft rejection in kidney. Am. J. Transplant. 1, 211-221.

Smith, C. R., Jaramillo, A., Liu, W., Tu, Y., Kaleem, Z., Swanson, C. J., and Mohanakumar, T. (2001). CD4 ${ }^{+}$T cell recognition of a single discordant HLA-A2-transgenic molecule through the indirect antigen presentation pathway induces acute rejection of murine cardiac allografts. Transplantation 71, 1640-1648.

Smyth, L. A., Afzali, B., Tsang, J., Lombardi, G., and Lechler, R. I. (2007). Intercellular transfer of MHC and immunological molecules: molecular mechanisms and biological significance. Am. J. Transplant. 7, 1442-1449.

Smyth, L. A., Herrera, O. B., Golshayan, D., Lombardi, G., and Lechler, R. I. (2006). A novel pathway of antigen presentation by dendritic and endothelial cells: Implications for allorecognition and infectious diseases. Transplantation 82, S15-S18.

Spadafora-Ferreira, M., Caldas, C., Fae, K. C., Marrero, I., Monteiro, S. M., Lin-Wang, H. T., SocorroSilva, A., Fonseca, S. G., Fonseca, J. A., Kalil, J., and Coelho, V. (2007). CD ${ }^{+}$CD $25^{+}$Foxp3 ${ }^{+}$indirect alloreactive $\mathrm{T}$ cells from renal transplant patients suppress both the direct and indirect pathways of allorecognition. Scand. J. Immunol. 66, 352-361.

Steinmann, J., Kaden, J., May, G., Schroder, K., Herwartz, C., and Muller-Ruchholtz, W. (1994). Failure of in vitro T-cell assays to predict clinical outcome after human kidney transplantation. J. Clin. Lab. Anal. 8, 157-162.

Suchin, E. J., Langmuir, P. B., Palmer, E., Sayegh, M. H., Wells, A. D., and Turka, L. A. (2001). Quantifying the frequency of alloreactive $\mathrm{T}$ cells in vivo: new answers to an old question. J. Immunol. 166, 973-981.

Suciu-Foca, N., Ciubotariu, R., Itescu, S., Rose, E. A., and Cortesini, R. (1998). Indirect allorecognition of donor HLA-DR peptides in chronic rejection of heart allografts. Transplant. Proc. 30, 3999-4000. 
Suciu-Foca, N., Liu, Z., Harris, P. E., Reed, E. F., Cohen, D. J., Benstein, J. A., Benvenisty, A. I., Mancini, D., Michler, R. E., Rose, E. A., et al. (1995). Indirect recognition of native HLA alloantigens and B-cell help. Transplant. Proc. 27, 455-456.

Suciu-Foca, N., Manavalan, J. S., and Cortesini, R. (2003). Generation and function of antigen-specific suppressor and regulatory $\mathrm{T}$ cells. Transpl. Immunol. 11, 235-244.

Sykes, M. (2007). Immune tolerance: mechanisms and application in clinical transplantation. J. Intern. Med. 262, 288-310.

Takatsuki, M., Uemoto, S., Inomata, Y., Sakamoto, S., Hayashi, M., Ueda, M., Kanematsu, T., and Tanaka, K. (2001). Analysis of alloreactivity and intragraft cytokine profiles in living donor liver transplant recipients with graft acceptance. Transpl. Immunol. 8, 279-286.

Taylor, A. L., Negus, S. L., Negus, M., Bolton, E. M., Bradley, J. A., and Pettigrew, G. J. (2007). Pathways of helper CD4 $\mathrm{T}$ cell allorecognition in generating alloantibody and CD8 T cell alloimmunity. Transplantation 83, 931-937.

Toyokawa, H., Nakao, A., Bailey, R. J., Nalesnik, M. A., Kaizu, T., Lemoine, J. L., Ikeda, A., Tomiyama, K., Papworth, G. D., Huang, L., Demetris, A. J., Starzl, T. E., and Murase, N. (2008). Relative contribution of direct and indirect allorecognition in developing tolerance after liver transplantation. Liver Transpl. 14, 346-357.

Trenado, A., Charlotte, F., Fisson, S., Yagello, M., Klatzmann, D., Salomon, B. L., and Cohen, J. L. (2003). Recipient-type specific $\mathrm{CD}^{+}{ }^{+} \mathrm{CD} 25^{+}$regulatory $\mathrm{T}$ cells favor immune reconstitution and control graft-versus-host disease while maintaining graft-versusleukemia. J. Clin. Invest. 112, 1688-1696.

Tsang, J. Y., Tanriver, Y., Jiang, S., Leung, E., Ratnasothy, K., Lombardi, G., and Lechler, R. (2009). Indefinite mouse heart allograft survival in recipient treated with CD4(+)CD25(+) regulatory $\mathrm{T}$ cells with indirect allospecificity and short term immunosuppression. Transpl. Immunol. 21, 203-209.

Van Hoffen, E., Polen, E., RobertusTeunissen, M., De Jonge, N., Lahpor, J. R., Gmelig-Meyling, F. H., and De Weger, R. A. (2000). High frequency of IL-4 producing helper $\mathrm{T}$ lymphocytes associated with a reduced incidence of heart allograft rejection. Transpl. Int. 13, S216-S224.

VanBuskirk, A. M., Burlingham, W. J., Jankowska-Gan, E., Chin, T., Kusaka, S., Geissler, F., Pelletier, R. P., and Orosz, C. G. (2000). Human allograft acceptance is associated with immune regulation. J. Clin. Invest. 106, 145-155.

Vella, J. P., Spadafora-Ferreira, M., Murphy, B., Alexander, S. I., Harmon, W., Carpenter, C. B., and Sayegh, M. H. (1997). Indirect allorecognition of major histocompatibility complex allopeptides in human renal transplant recipients with chronic graft dysfunction. Transplantation 64, 795-800.

Velthuis, J. H., Hesselink, D. A., Hendrikx, T. K., Van Der Mast, B. J., Klepper, M., De Greef, G. E., Baan, C. C., and Weimar, W. (2007). Kinetic analysis reveals potency of $\mathrm{CD} 4{ }^{+} \mathrm{CD} 25^{\text {bright }}+$ regulatory $\mathrm{T}$ cells in kidney transplant patients. Transpl. Immunol. 18, 159-165.

Velthuis, J. H., Mol, W. M., Weimar, W., and Baan, C. C. (2006) $\mathrm{CD} 4{ }^{+} \mathrm{CD} 25^{\text {bright }}+$ regulatory $\mathrm{T}$ cells can mediate donor nonreactivity in long-term immunosuppressed kidney allograft patients. Am. J. Transplant. 6, 2955-2964.

Waanders, M. M., Heidt, S., Koekkoek, K. M., Zoet, Y. M., Doxiadis, I. I. N., Amir, A., Heemskerk, M. H M., Mulder, A., Brand, A., Roelen, D. L., and Claas, F. H. J. (2008). Monitoring of indirect allorecognition: wishful thinking or solid data? Tissue Antigens 71, 1-15.

Waldmann, H., Adams, E., Fairchild, P., and Cobbold, S. (2006). Infectious tolerance and the long-term acceptance of transplanted tissue. Immunol. Rev. 212, 301-313.

Walker, L. S., Chodos, A., Eggena, M., Dooms, H., and Abbas, A. K. (2003). Antigen-dependent proliferation of
$\mathrm{CD}^{+}{ }^{+} \mathrm{CD} 25^{+}$regulatory $\mathrm{T}$ cells in vivo. J. Exp. Med. 198, 249-258.

Wang, C., Cordoba, S., Hu, M. Bertolino, P., Bowen, D. G. Sharland, A. F., Allen, R. D. Alexander, S. I., McCaughan, G. W., and Bishop, G. A. (2011). Spontaneous acceptance of mouse kidney allografts is associated with increased Foxp3 expression and differences in the $\mathrm{B}$ and $\mathrm{T}$ cell compartments. Transpl. Immunol. 24, 149-156.

Weber, D. A., Terrell, N. K., Zhang, Y., Strindberg, G., Martin, J., Rudensky, A., and Braunstein, N. S. (1995). Requirement for peptide in alloreactive $\mathrm{CD}^{+}{ }^{+} \mathrm{T}$ cell recognition of class II MHC molecules. J. Immunol. 154, 5153-5164.

Weiss, M. J., Guenther, D. A., Mezrich, J. D., Sahara, H., Ng, C. Y., Meltzer, A. J., Sayre, J. K., Cochrane, M. E., Pujara, A. C., Houser, S. L., Sachs, D. H., Rosengard, B. R., Allan, J. S., Benichou, G., and Madsen, J. C. (2009). The indirect alloresponse impairs the induction but not maintenance of tolerance to MHC class I-disparate allografts. Am. J. Transplant. 9, 105-113.

Wise, M. P., Bemelman, F., Cobbold, S. P., and Waldmann, H. (1998) Linked suppression of skin graft rejection can operate through indirect recognition. J. Immunol. 161, 5813-5816.

Wollenberg, I., Agua-Doce, A., Hernandez, A., Almeida, C. Oliveira, V. G., Faro, J., and Graca, L. (2011). Regulation of the germinal center reaction by Foxp3 $3^{+}$ follicular regulatory $\mathrm{T}$ cells. $J$. Immunol. 187, 4553-4560.

Wood, K. J., Bushell, A., and Jones, N. D. (2011). Immunologic unresponsiveness to alloantigen in vivo: a role for regulatory T cells. Immunol. Rev. 241, 119-132.

Yamada, A., Chandraker, A., Laufer, T. M., Gerth, A. J., Sayegh, M. H., and Auchincloss, H. Jr. (2001). Recipient MHC class II expression is required to achieve long-term survival of murine cardiac allografts after costimulatory blockade. J. Immunol. $167,5522-5526$.
Yamada, Y., Boskovic, S., Aoyama, A., Murakami, T., Putheti, P., Smith, R. N., Ochiai, T., Nadazdin, O. Koyama, I., Boenisch, O., Najafian, N., Bhasin, M. K., Colvin, R. B., Madsen, J. C., Strom, T. B., Sachs, D. H., Benichou, G., Cosimi, A. B., and Kawai, T. (2012). Overcoming memory T-cell responses for induction of delayed tolerance in nonhuman primates. Am. J. Transplant. 12, 330-340.

Yang, J., Brook, M. O., CarvalhoGaspar, M., Zhang, J., Ramon, H. E., Sayegh, M. H., Wood, K. J., Turka, L. A., and Jones, N. D. (2007). Allograft rejection mediated by memory $\mathrm{T}$ cells is resistant to regulation. Proc. Natl. Acad. Sci. U.S.A. 104, 19954-19959.

Yoshizawa, A., Ito, A., Li, Y., Koshiba, T., Sakaguchi, S., Wood, K. J., and Tanaka, K. (2005). The roles of $\mathrm{CD}_{2} 5^{+} \mathrm{CD} 4{ }^{+}$regulatory $\mathrm{T}$ cells in operational tolerance after living donor liver transplantation. Transplant. Proc. 37, 37-39.

Conflict of Interest Statement: The authors declare that the research was conducted in the absence of any commercial or financial relationships that could be construed as a potential conflict of interest.

Received: 23 April 2012; accepted: 14 June 2012; published online: 13 July 2012.

Citation: Sagoo P, Lombardi $G$ and Lechler RI (2012) Relevance of regulatory $T$ cell promotion of donor-specific tolerance in solid organ transplantation. Front. Immun. 3:184. doi: 10.3389/ fimmu.2012.00184

This article was submitted to Frontiers in Immunological Tolerance, a specialty of Frontiers in Immunology. Copyright (c) 2012 Sagoo, Lombardi and Lechler. This is an open-access article distributed under the terms of the Creative Commons Attribution License, which permits use, distribution and reproduction in other forums, provided the original authors and source are credited and subject to any copyright notices concerning any third-party graphics etc. 